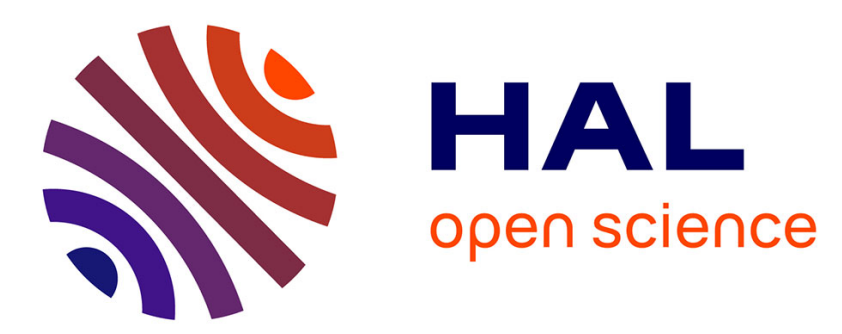

\title{
Catalytic challenges and strategies for the carbonylation of $\sigma$-bonds
}

Tawfiq Nasr Allah, Louise Ponsard, Emmanuel Nicolas, Thibault Cantat

\section{To cite this version:}

Tawfiq Nasr Allah, Louise Ponsard, Emmanuel Nicolas, Thibault Cantat. Catalytic challenges and strategies for the carbonylation of $\sigma$-bonds. Green Chemistry, In press, 23, pp.723-739. $10.1039 / \mathrm{d} 0 \mathrm{gc} 02343 \mathrm{~d}$. cea-03096007

\section{HAL Id: cea-03096007 https://hal-cea.archives-ouvertes.fr/cea-03096007}

Submitted on 4 Jan 2021

HAL is a multi-disciplinary open access archive for the deposit and dissemination of scientific research documents, whether they are published or not. The documents may come from teaching and research institutions in France or abroad, or from public or private research centers.
L'archive ouverte pluridisciplinaire HAL, est destinée au dépôt et à la diffusion de documents scientifiques de niveau recherche, publiés ou non, émanant des établissements d'enseignement et de recherche français ou étrangers, des laboratoires publics ou privés. 


\title{
Catalytic challenges and strategies for the carbonylation of $\sigma$-bonds
}

\author{
Tawfiq Nasr Allah†, Louise Ponsard†, Emmanuel Nicolas and Thibault Cantat*a \\ The carbene character of carbon monoxide offers the possibility to utilize this $\mathrm{C}_{1}$-building block for the carbonylation of a \\ variety of organic substrates by insertion of $\mathrm{CO}$ into $\sigma$-bonds. Although presenting an ideal atom economy this route requires \\ the design and utilization of reactive catalysts able to activate strong $\mathrm{C}-\mathrm{O}, \mathrm{C}-\mathrm{N}$, and $\mathrm{C}-\mathrm{H}$ bonds in the presence of carbon \\ monoxide. This perspective article adresses, in the context of sustainable chemistry, the challenges and strategies facing the \\ catalytic carbonylation of $\sigma$-bonds and presents the key advances in the field over the last decades, for the carbonylation \\ polar and apolar substrates, such as the conversion of alcohols to formates and esters and the carbonylation of amines to \\ amides.
}

\section{Introduction}

The chemical industry is heavily dependent on oil-based resources, the latter being required for the synthesis of $87 \%$ of chemicals in 2016. ${ }^{1}$ To reduce this need and engage into a circular economy pathway, which would ultimately lead to its carbon-neutrality, it would be attractive to synthesize chemicals directly from $\mathrm{CO}_{2}$. Nevertheless, the direct use of $\mathrm{CO}_{2}$ for the production of functionalized chemicals remains limited in industry: its use as a $C_{1}$ building block for the production of chemicals has been well developed for the production of urea (81 Mt in 2016), salicylic acid (70 kt/y), and more recently for the production of cyclic and polymeric carbonates $(130 \mathrm{k} / \mathrm{y}) .^{2}$ These transformations implicate the functionalization of $\mathrm{CO}_{2}$, but only chemicals containing a carbon at the +IV oxidation state have been industrially synthesized so far. Accessing other chemicals directly from $\mathrm{CO}_{2}$ would require synchronizing reduction and functionalization, which is an active field of research but is difficult to control. An interesting intermediate would be carbon monoxide (CO) that can provide access to functionalized chemicals at a more reduced oxidation state, + II, closer to the average oxidation state of most industrial chemicals.

Carbon monoxide (CO) is a colourless gas that already finds many uses in the chemical industry, despite its high toxicity. ${ }^{3}$ For instance, the Mond process for the purification of nickel, the oxo process for the production of aldehydes from alkenes, or Fischer-Tropsch process for the synthesis of alkanes from syngas (mixtures of $\mathrm{CO}$ and $\mathrm{H}_{2}$ ) have been industrialized over the past century, and are used on a megaton scale throughout

\footnotetext{
a. Dr T. Nasr Allah, L Ponsard, DrE. Nicolas, Dr T. Cantat Université Paris-Saclay, CEA, CNRS, NIMBE, CEA Saclay 91191 Gif-sur-Yvette cedex, France

E-mail: thibault.cantat@cea.fr.

† These authors contributed equally
}

the world. ${ }^{4}$ Nevertheless, the CO produced for these applications derives mainly from fossil resources, through methane steam reforming or dry reforming. ${ }^{5}$

A promising route based on renewable carbon sources through biomass gasification enables the production of $\mathrm{CO}$ or syngas. ${ }^{6}$ This pathway could enlarge to the gasification of carbon waste streams such as mixtures of plastics or chemicals that cannot be separated. ${ }^{7}$ The deoxygenation of biomass by decarbonylation for the production of high value substrates generates a highly concentrated flow of $\mathrm{CO}^{8}$

Moreover, $\mathrm{CO}_{2}$ conversion to $\mathrm{CO}$ is a highly active field of research, which could provide for a more sustainable source of $\mathrm{CO}$ in the near future. ${ }^{9}$ In particular, large amounts of $\mathrm{CO}_{2}$ (41 Mt/yr) are produced upon anaerobic digestion of biomass which produces a gas stream with ca. $65 \%$ methane and $35 \%$ $\mathrm{CO}_{2} \cdot{ }^{10}$ Its conversion into $\mathrm{CO}$ is well-known through reverse water-gas shit (RWGS), and, examples of electroreduction or photoreduction of $\mathrm{CO}_{2}$ have been developed in the past decade. ${ }^{11}$ Electroreduction would especially be of interest, and if one considers the few main processes that use $\mathrm{CO}$ (consuming approximately $55 \mathrm{Mt} /$ year for the production of methanol, butanal, acetic acid and phosgene), ${ }^{12}$ a full shift of its production from fossil resources to $\mathrm{CO}_{2}$ electroreduction would consume approximately $2-3 \%$ of the global electric production, which is comparable to the world aluminum or chlorine production. ${ }^{13}$ $\mathrm{CO}$ can thus be considered as a key intermediate for the production of chemicals from $\mathrm{CO}_{2}$ and alternative carbon sources. The wide usage of $\mathrm{CO}$ for the synthesis of organic chemicals can be attributed to its specific chemical properties. $\mathrm{CO}$ indeed displays a carbenic character, with its HOMO and LUMO being both centred on the carbon atom. Its use for the insertion of a $\mathrm{C}=\mathrm{O}$ group into covalent bonds is thus favoured compared to using $\mathrm{CO}_{2}$, where a $\mathrm{C}-\mathrm{O}$ bond will need cleaving. 


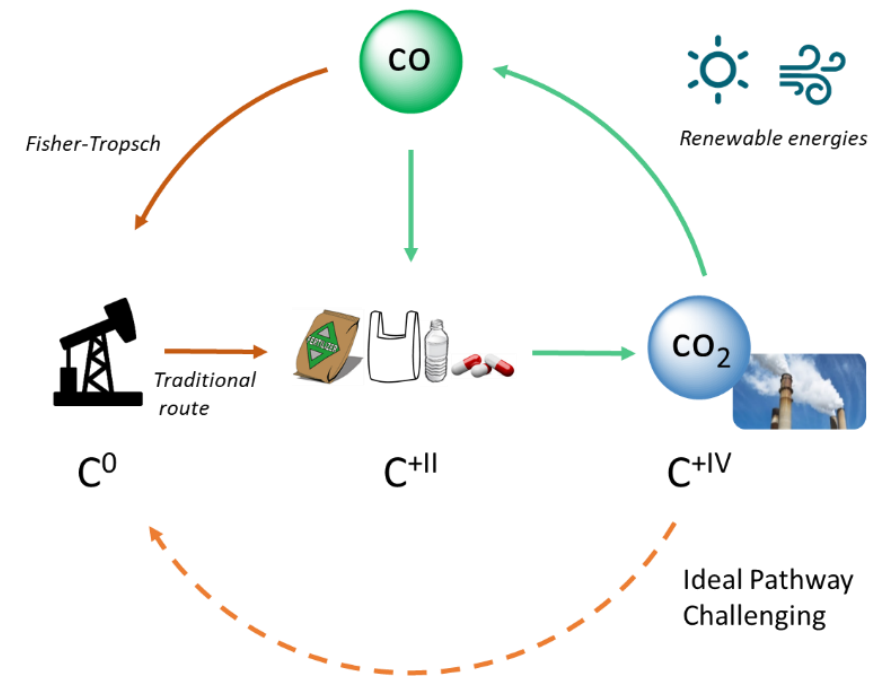

Figure 1: Principle of the use of $\mathrm{CO}$ as a $\mathrm{C}_{1}$ intermediate from $\mathrm{CO}_{2}$.

Carbonylative cross-coupling reactions have been successfully developed and implemented in organic chemistry, to prepare carbonyl functional groups via the metal-catalyzed coupling of a nucleophile with an electrophile, under an atmosphere of CO. This topic has been widely reviewed over the last years. ${ }^{14}$ This synthetic route is however hampered by the formation of stoichiometric amounts of by-products, in the form of inorganic salts that derive from the utilization of the two partners. In contrast, the direct insertion of a $\mathrm{C}=\mathrm{O}$ group in a $\sigma$-bond of an organic molecule is a highly desirable reaction that would avoid the use of strong, usually toxic, oxidants for the synthesis of various $\mathrm{C}=\mathrm{O}$ containing compounds. In an atom-economy perspective, this method provides the most efficient pathway for the synthesis of various carbonylated derivatives. To this end, the ideal catalytic carbonylation sequence would rely on three steps (Scheme 1, top): the activation of a $\sigma$ bond, insertion of $\mathrm{CO}$ in one metal-ligand bond, prior to an elimination step that provides the carbonylated product. In this scenario, the challenge mainly relies on the selective activation of a $\sigma$ bond. The presence of low-lying $\pi^{*}$ orbitals in CO, constrains the utilization of strongly reducing metal ion, which could activate strong $\sigma$ bonds by oxidative addition processes by accessing the $\sigma^{*}$ orbital of the substrate (Scheme 1 , bottom). In addition, the presence of several $\sigma^{*}$ orbitals in the substrate, corresponding to different $\sigma$ bonds, may lead to selectivity issues. To tackle the challenges associated with the carbonylation of $\sigma$ bonds, catalytic strategies must hence be designed.

In this perspective, we discuss the existing literature relative to the carbonylation of $\sigma$-bonds, demonstrating with relevant examples how it is an efficient way to synthesize carbonylated compounds such as esters, ketones, or amides. The chosen examples will highlight the different catalytic strategies engaged to activate the $\sigma$-bond, enabling subsequent carbonylation, with a particular focus on mechanisms. First, the carbonylation of polar bonds, more easily activated, is described, starting with $\mathrm{O}-\mathrm{H}$ and $\mathrm{C}-\mathrm{O}$ bonds, with an emphasis on an industrially relevant substrate: methanol. Second, existing methods for the carbonylation of $\mathrm{N}-\mathrm{H}$ and $\mathrm{C}-\mathrm{N}$ bonds, and related carbon-halogen bonds, is presented. Finally, we review the carbonylation of apolar bonds, starting with dihalogens and $\mathrm{H}_{2}$, to conclude with the last progresses in the field of the carbonylation of $\mathrm{C}-\mathrm{C}$ and $\mathrm{C}-\mathrm{H}$ bonds.

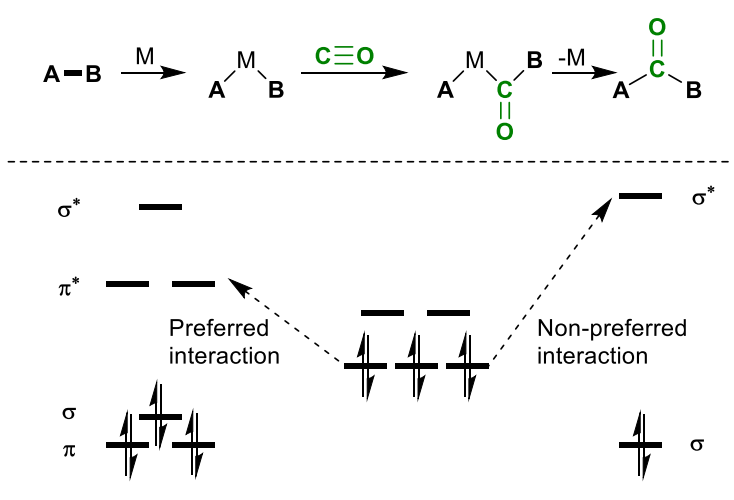

C $\equiv$ O Metallic centre $\quad$ A-B

Scheme 1: Top: Ideal carbonylation sequence; Bottom: Preferred orbital interactions between a metal centre and a substrate (A-B), in the presence of $C O$.

\section{Carbonylation of polar substrates}

\subsection{Activation strategies for the carbonylation of polar $\sigma$-bonds}

The catalytic carbonylation of polar $\sigma$-bonds is the preferred method to reach carbonyl-containing compounds with good atom economy. To unlock the potential of this approach, strategies have been developed that involve the use of various additives. For instance, Lewis acids can coordinate to the oxygen atom of a $\mathrm{C}-\mathrm{O}$ bond, to facilitate its activation. Alternatively, the in situ conversion of strong $\mathrm{C}-\mathrm{O}$ bonds to a weaker $\mathrm{C}-\mathrm{I}$ bond is a successful route for the carbonylation of alcohols and ethers, as exemplified in the Monsanto and Cativa processes for the production of acetic acid from methanol (vide infra).

\subsection{Carbonylation of methanol}

While methanol is currently produced from methane through syngas, this $\mathrm{C}_{1}$ compound can also be produced from biomass or $\mathrm{CO}_{2}$ hydrogenation. ${ }^{12 \mathrm{C}}$ In a methanol economy, it is expected to serve as a vector for energy storage, as a liquid fuel for transport and as a feedstock for the downstream production of chemicals. ${ }^{15}$ Its carbonylation can lead to two different compounds that are used in industrial processes: methyl formate results from the carbonylation of the $\mathrm{O}-\mathrm{H}$ bond, while acetic acid is formed upon insertion of $\mathrm{CO}$ into the $\mathrm{C}-\mathrm{O}$ bond (Scheme 2).

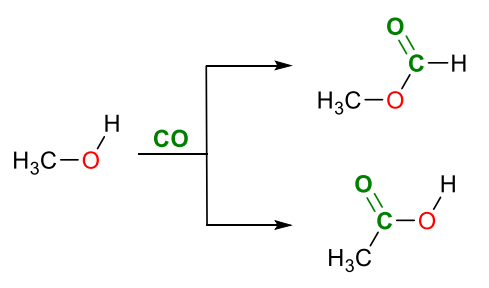

Scheme 2: Carbonylation of methanol to methyl formate or acetic acid 


\section{Carbonylation of the $\mathrm{O}-\mathrm{H}$ bond of methanol}

The insertion of carbon monoxide into the $\mathrm{O}-\mathrm{H}$ bond of methanol leads to methyl formate, a starting material to formic acid, formamide and dimethylformamide. ${ }^{16}$ BASF reported in 1926 the first example of a carbonylation of an $\mathrm{O}-\mathrm{H}$ bond, using sodium methoxide as a catalyst. Efficient carbonylation was observed after a few hours at $80{ }^{\circ} \mathrm{C}$, under 200 bar of $\mathrm{CO} .{ }^{17} \mathrm{It}$ has been shown that the ionization potential of the alkali cation influences the formation of the alkoxide anion and therefore the rate of the reaction, which increased with the size of the alkali ion $(\mathrm{Li}<\mathrm{Na}<\mathrm{K}) .{ }^{18}$ The catalytic sequence involves the nucleophilic attack of an electron-rich alkoxide onto the carbon atom of $\mathrm{CO}$ to form the corresponding acyl anion. The latter is a strong Brønsted base, able to deprotonate methanol to yield methyl formate and regenerate the methoxide catalyst. The chain length of the alcohol and the degree of substitution close to the hydroxyl group have a strong influence on the rate of the reaction: this is confirmed by the poor reactivity of benzyl alcohol, a weaker nucleophile than methanol. Interestingly, the carbonylation of the $\mathrm{O}-\mathrm{H}$ bond is one of the only examples which does not require any co-catalyst to activate the $\sigma$-bond, and is easily cleaved by a strong Brønsted base. Nevertheless, the assistance of a metal carbonyl, such as $\mathrm{W}(\mathrm{CO})_{6},{ }^{19}$ $\mathrm{Ru}_{3}(\mathrm{CO})_{12},{ }^{20}$ or $\mathrm{Mo}(\mathrm{CO})_{6},{ }^{21}$ improves the reaction rate by enhancing the electrophilicity of the $\mathrm{CO}$ carbon atom and facilitating the outer sphere nucleophilic attack of the alkoxide anion (Scheme 3).
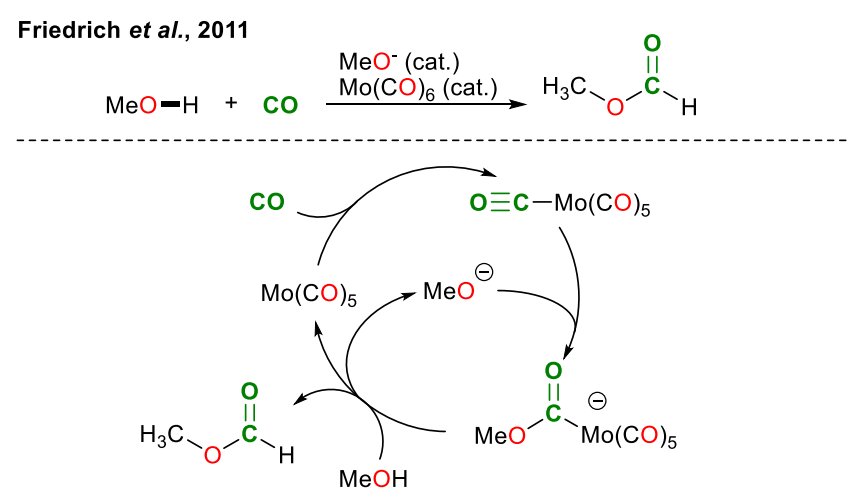

Scheme 3: Catalytic carbonylation of the $\mathrm{O}-\mathrm{H}$ bond of methanol, assisted by a low valent metal-carbonyl complex $\left(\mathrm{Mo}(\mathrm{CO})_{6}\right)$

Tabb et al. reported in 1984 the selective carbonylation of methanol into methyl formate, using a platinum-based catalyst, at $170^{\circ} \mathrm{C}$ under 76 bar. This catalytic system proceeds via a completely different mechanism (Scheme 4), ${ }^{22}$ which was studied based on in-situ IR spectroscopy and supported by previous results from the literature. ${ }^{23}$ After its in-situ synthesis, the $\mathrm{Pt}^{0}$ complex $\left[\mathrm{Pt}(\mathrm{CO})_{2}\left(\mathrm{PR}_{3}\right)_{2}\right]$ was shown to activate $\mathrm{MeOH}$ through an oxidative addition in the $\mathrm{O}-\mathrm{H}$ bond, to form $\left[\mathrm{Pt}(\mathrm{H})(\mathrm{OMe})\left(\mathrm{PR}_{3}\right)_{2}\right]$. In that case, an oxidative addition of the metallic centre into the $\mathrm{O}-\mathrm{H}$ bond was in fact observed, resulting in an inner-sphere mechanism in contrast with the outer sphere nucleophilic attack previously described. The platinum complex $\left[\mathrm{Pt}(\mathrm{H})(\mathrm{C}(\mathrm{O}) \mathrm{OMe})\left(\mathrm{PR}_{3}\right)_{2}\right]$ is then formed by insertion under CO pressure. Finally, reductive elimination of methyl formate regenerates the catalyst. ${ }^{24}$

In both types of mechanism reported for the carbonylation of an $\mathrm{O}-\mathrm{H}$ bond, assistance of a co-catalyst is not required. Indeed, the cleavage of this bond can be easily performed under mild conditions.

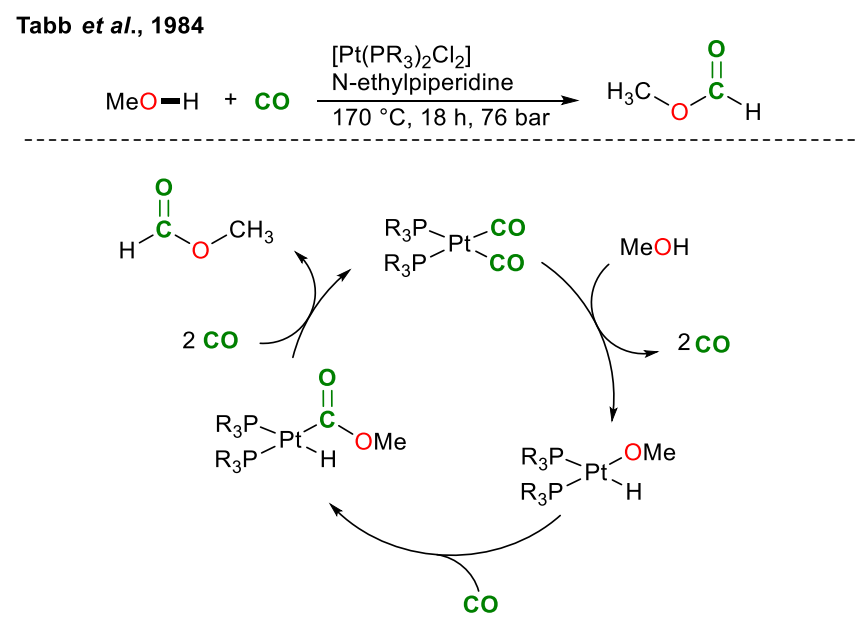

Scheme 4: Platinum catalyzed carbonylation of methanol to methyl formate

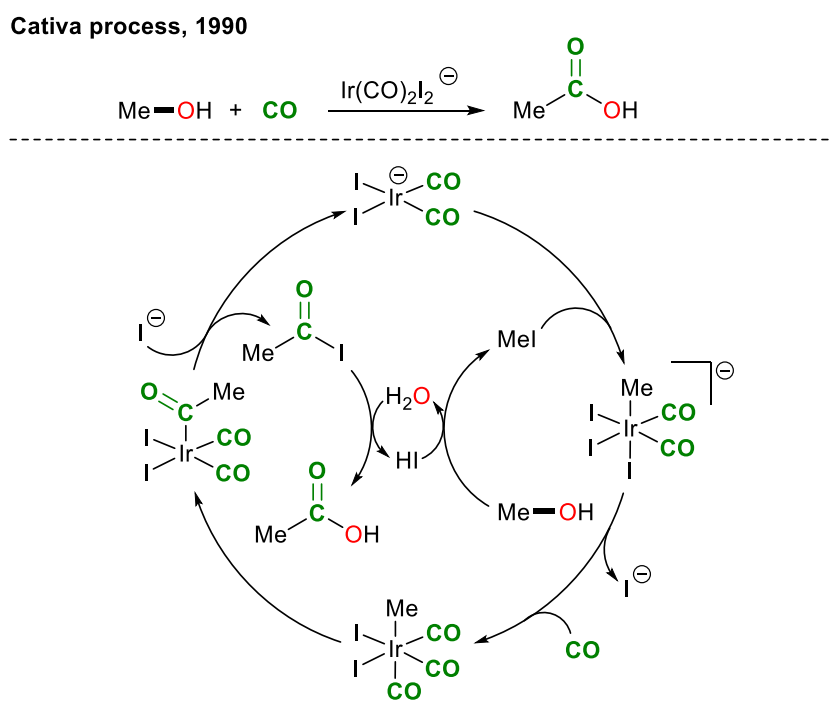

Scheme 5: The Cativa process for the carbonylation of methanol

\section{Carbonylation of the $\mathrm{C}-\mathrm{O}$ bond of the methanol}

The carbonylation of the $\mathrm{C}-\mathrm{O}$ bond of methanol leads to acetic acid, used as a solvent or starting material for various industrial fine chemicals, such as vinyl acetate or acetic anhydride. ${ }^{12 b}$ In 2012, 90\% of the global production of acetic acid (ca. $8 \mathrm{Mt} / \mathrm{y}$ ) was achieved through methanol carbonylation. The direct carbonylation of a $\sigma \mathrm{C}-\mathrm{O}$ bond has, to the best of our knowledge, never been observed despite its lower bond dissociation energy ( $\mathrm{BDE}=377$ vs. $437 \mathrm{~kJ}^{\mathrm{mol}} \mathrm{m}^{-1}$ for $\mathrm{C}-\mathrm{O}$ vs $\mathrm{O}-\mathrm{H}$ bonds in $\mathrm{MeOH}),{ }^{25}$ the activation of the $\mathrm{O}-\mathrm{H}$ bond being usually kinetically favoured. To circumvent this issue, it is necessary to convert the alcohol to its corresponding iodide, thereby replacing the $\mathrm{C}-\mathrm{O}$ bond by a weaker $\mathrm{C}-\mathrm{I}$ bond $\left(\mathrm{BDE}=232 \mathrm{~kJ} . \mathrm{mol}^{-}\right.$ 
$\left.{ }^{1}\right)$. The latter can be carbonylated through a classical catalytic sequence of oxidative addition / migratory insertion in a metal carbon bond / reductive elimination of the acyl iodide. ${ }^{16 \mathrm{~b}}$

The first catalytic process for the carbonylation of methanol was reported by BASF in 1955, using harsh conditions ( 680 bar CO, $250{ }^{\circ} \mathrm{C}$ ) despite the use of cobalt ${ }^{26}$ or nickel ${ }^{27}$ combined with an iodide source as catalyst, leading to the $90 \%$-selective formation of acetic acid. In the following decades, $\mathrm{Rh}^{28}$ and $\mathrm{Ir}^{29}$ have been reported as alternative efficient catalysts. The most used catalytic processes, with Rh (Monsanto process) and Ir (Cativa process) exploit very similar mechanisms and both use iodide promoters. ${ }^{30}$ The Monsanto process developed in the late sixties typically runs at $150-200{ }^{\circ} \mathrm{C}$, under $30-60$ bar $\mathrm{CO}$, but has been gradually replaced in the late nineties by the energetically less demanding Cativa process that runs at 20-25 bar and $200{ }^{\circ} \mathrm{C}$, using a more stable Ir complex. The mechanism for the Cativa process is an excellent example of the $\mathrm{C}-\mathrm{O} / \mathrm{C}-\mathrm{I}$ replacement that helps the carbonylation reaction. First, hydrogen iodide, additive of the reaction, reacts with methanol to form water and methyl iodide. The latter then reacts with $\left[\operatorname{Ir}(\mathrm{CO})_{2} \mathrm{I}_{2}\right]^{-}$to yield a methyl complex. This complex undergoes a ligand substitution, from iodide to carbonyl, to generate $\left[\operatorname{Ir}(\mathrm{Me})(\mathrm{CO})_{3} l_{2}\right]$, which further evolves to an acyl complex $\left[\operatorname{Ir}(\mathrm{C}(\mathrm{O}) \mathrm{Me})(\mathrm{CO})_{2} \mathrm{I}_{2}\right]$ through a migratory insertion step, constituting the rate determining step, in contrast with the Monsanto process, that is limited by the oxidative addition of methyl iodide to the rhodium centre. Addition/elimination of an iodide on the acyl moiety regenerates the starting catalyst and acetyl iodide, which is hydrolysed to acetic acid, completing the carbonylation sequence. ${ }^{31}$ Following this process, methanol is converted to methyl iodide, which is actually carbonylated, taking advantage of its enhanced reactivity with the iridium catalyst (Scheme 5). The addition of a promoter such as a ruthenium salt has been reported to convert the ionic methyl complex $\left[\operatorname{Ir}(\mathrm{Me})(\mathrm{CO})_{2} l_{3}\right]^{-}$to the neutral species $\left[\operatorname{Ir}(\mathrm{Me})(\mathrm{CO})_{3} \mathrm{I}_{2}\right]$ for which the migration of the methyl is faster. ${ }^{32}$

\section{Carbonylation of the $\mathbf{C}-\mathbf{O}$ bond of higher alcohols}

As for methanol, higher alcohols, such as ethanol, are easily produced from biomass, by sugar or starch fermentation ( $1^{\text {st }}$ generation) or by hydrolysis and fermentation of lignocellulosic material ( $2^{\text {nd }}$ generation). ${ }^{33}$ The production of carboxylic acids by bio-based alcohols carbonylation would then constitute a sustainable and atom-economic pathway. The carbonylation of higher alcohols was explored with a rhodium-based catalyst assisted by hydrogen iodide. Nevertheless, high temperatures are required and the rate of the reaction decreases significantly with a growing chain, where ethanol and propanol were carbonylated 21 and 45 times slower than methanol respectively, effectively preventing the carbonylation of more complex substrates. ${ }^{34}$ This observation is consistent with the relative speeds of oxidative addition of the alkyl iodides on rhodium. The development of more reactive, but also acid-free, catalytic systems able to proceed in mild conditions is thus required to extend the scope to longer chain and functionalized alcohols. In parallel, strategies for the carbonylation of activated $\mathrm{C}-\mathrm{O}$ bonds in milder conditions were developed.

\subsection{Carbonylation of activated $\mathrm{C}-\mathrm{O}$ bonds}

\section{Carbonylation of strained cyclic ethers}

The direct carbonylation of an endocyclic $\mathrm{C}-\mathrm{O}$ bond through ring-expansion leads to the corresponding lactone, a class of chemicals commonly used as monomers for the production of biodegradable polyesters. ${ }^{35}$ Although the release of the cyclic strain, induced upon insertion of a $\mathrm{C}=\mathrm{O}$ moiety in the $\mathrm{C}-\mathrm{O}$ bond, facilitates the reaction, an activation of the $\sigma$-bond by a Lewis acid is required.

$$
\mathrm{O}_{\mathrm{n}}+\mathrm{co} \longrightarrow \text { cat. } \longrightarrow \stackrel{O-c^{\prime \prime}}{L} \mathrm{l}_{\mathrm{n}} \mathrm{n}=1 \text { or } 2
$$

Scheme 6: Synthesis of lactones by carbonylation of $\mathrm{C}-\mathrm{O}$ bonds in cyclic ethers

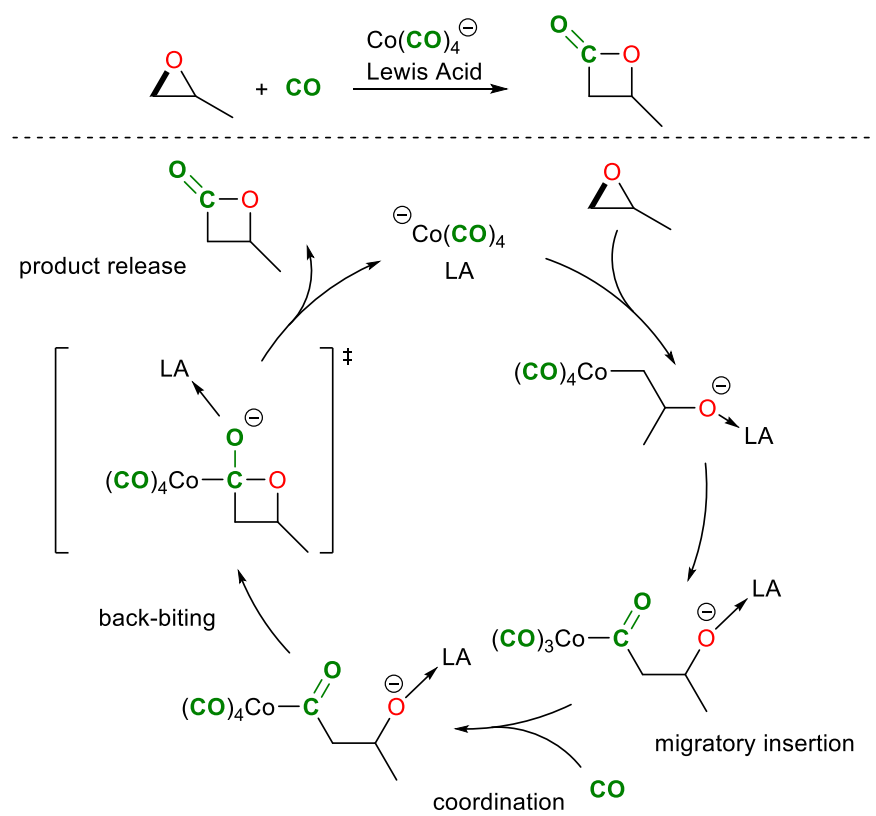

$\mathrm{LA}=$ Lewis Acid $\left(\mathrm{BF}_{3}-\mathrm{Et}_{2} \mathrm{O}\right.$, Tetraphenylporhyrin Chromium, Phthalocyanine Aluminium, etc)

Scheme 7: Mechanism for the cobalt-catalyzed carbonylation of epoxides

The direct carbonylation of an epoxide through ring-expansion leads to a four-membered lactone, which is an important monomer and a precursor to acrylic acid. ${ }^{36}$ Most catalytic systems for this transformation are based on the combination of cobaltate carbonyl $\left[\mathrm{Co}(\mathrm{CO})_{4}\right]$, , with a Lewis acid that is required to activate the $\sigma$-bond and allow the opening of the epoxide. Only few Lewis acids have been described. The group of Alper reported the first example with boron trifluoride, yet high $\mathrm{CO}$ pressure was required (60 bar of $\mathrm{CO}$ ). ${ }^{37}$ Over the last two decades, the group of Coates has reported that the use of organometallic Lewis acids allows mild reaction conditions, with the possibility to carry out the carbonylation of propylene oxide at $22{ }^{\circ} \mathrm{C}$, with 1 bar $\mathrm{CO}$. The Lewis acid plays a key role in the catalytic cycle, where it improves the kinetics and the selectivity of the reaction, by preventing $\beta$-hydride eliminations (leading to acetone, product of the Meinwald rearrangement) and polymerization of the epoxide to polyethers. The best catalyst 
reported involved [salphCr][Co(CO $\left.)_{4}\right]$. It is able to convert propylene oxide to $\beta$-butyrolactone with more than $98 \%$ yield under 1 bar of $\mathrm{CO}^{38}$

The same strategy can be applied for the carbonylation of oxetane. The first example has been reported by Alper et al. using cobalt carbonyl catalyst assisted by ruthenium carbonyl at $190{ }^{\circ} \mathrm{C}$ and $60 \mathrm{~atm}$ for 2 days in 1,2-dimethoxyethane to afford $\gamma$-butyrolactone. ${ }^{39} \mathrm{~A}$ few years later, Coates et al. demonstrated the activity of the [salphAl] $\left[\mathrm{Co}(\mathrm{CO})_{4}\right]$ complex already known for epoxide carbonylation with slightly different reaction conditions ( 14 bar of $\mathrm{CO}, 80^{\circ} \mathrm{C}, 24 \mathrm{~h}$ in toluene)..$^{40}$ Thanks to the activation of the $\sigma$-bond by a Lewis Acid, the carbonylation of oxetane proceeds easily under milder conditions. Nevertheless, the carbonylation of larger rings requires harsher conditions or stronger activation: the carbonylation of tetrahydrofuran has been reported to be catalyzed by $\mathrm{Co}(\mathrm{Ac})_{2}$ at $200{ }^{\circ} \mathrm{C}$, under $200 \mathrm{~atm}$ of $\mathrm{CO} / \mathrm{H}_{2}$ or with the Monsanto catalytic systems (Rh, source of iodine, $230{ }^{\circ} \mathrm{C}, 130$ bar of CO)..$^{41}$

Carbonylation of strained cyclic esters

Yoon et al., 2019

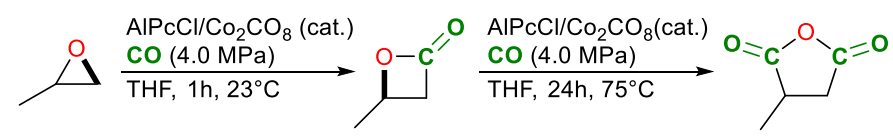

Scheme 8: Double carbonylation of epoxide to methylsuccinic anhydride

The carbonylation of lactones is a direct pathway for the formation of cyclic anhydrides, widely used as monomers for the production of polyester by copolymerization. ${ }^{42}$ This reaction is performed using similar catalytic systems as used for the carbonylation of epoxides, with only slightly different conditions. ${ }^{40,43}$ The $\mathrm{C}-\mathrm{O}$ bond cleavage of the lactone requires indeed a higher energy than the one of epoxides due to its lower ring strain. For instance, Yoon et al. reported very recently that a cobalt carbonyl catalyst associated with an aluminum phthalocyanine co-catalyst could perform the single carbonylation of propylene oxide to the corresponding lactone at room temperature within one hour. When the reaction medium was then heated at $75^{\circ} \mathrm{C}$ for $24 \mathrm{~h}$, the insertion of a second $\mathrm{C}=\mathrm{O}$ moiety was observed, leading to formation of methyl succinic anhydride. ${ }^{44}$ (Scheme 8)

The carbonylation of $\beta$-lactone proceeds via similar mechanistic pathway as the carbonylation of epoxides. The carbonylation of lactones with $>5$ membered rings has however not been observed. In these cases, the cleavage of the other $\mathrm{C}-\mathrm{O}$ bond in the molecule is favoured, leading to polymerization rather than carbonylation. ${ }^{45}$

\section{Carbonylation of benzylic and allylic $\mathrm{C}-\mathrm{O}$ bonds}

Benzylic and allylic $\mathrm{C}-\mathrm{O} \sigma$-bonds are intrinsically more active than phenyl or alkyl ones because the heterolytic cleavage of the $\mathrm{C}-\mathrm{O}$ bond generates a stabilized benzylic or allylic cation. Nonetheless, their carbonylation still requires an external activation. Yamamoto et al. described in 1997 the carbonylation of benzylic $\mathrm{C}-\mathrm{O}$ bond with $\mathrm{Pd} / \mathrm{PPh}_{3}$ based catalyst. ${ }^{46}$ Despite the already activated $\mathrm{C}-\mathrm{O}$ bond, the reaction requires not only 90 bar of $\mathrm{CO}$ at $90{ }^{\circ} \mathrm{C}$ for 44 hours in an aqueous system, but also the use of hydriodic acid. The catalysis proceeds according to a mechanism similar to the Monsanto process, with the intermediate formation of benzyl iodide (vide supra, Scheme 5). ${ }^{47}$ The carbonylation of 5-hydroxymethylfurfural (HMF) to the corresponding acid was reported by the group of Sheldon, at $70{ }^{\circ} \mathrm{C}$ under $5 \mathrm{bar}$, in the presence of sulphuric acid and a palladium catalyst in water. ${ }^{48}$ Interestingly, the carbonylation of the benzylic $\mathrm{C}-\mathrm{O}$ bond of 1-(4-isobutylphenyl)ethanol has been developed as this results in the formation of 2-(4isobutylphenyl)propionic acid, also known as ibuprofen (Scheme 9). ${ }^{49}$

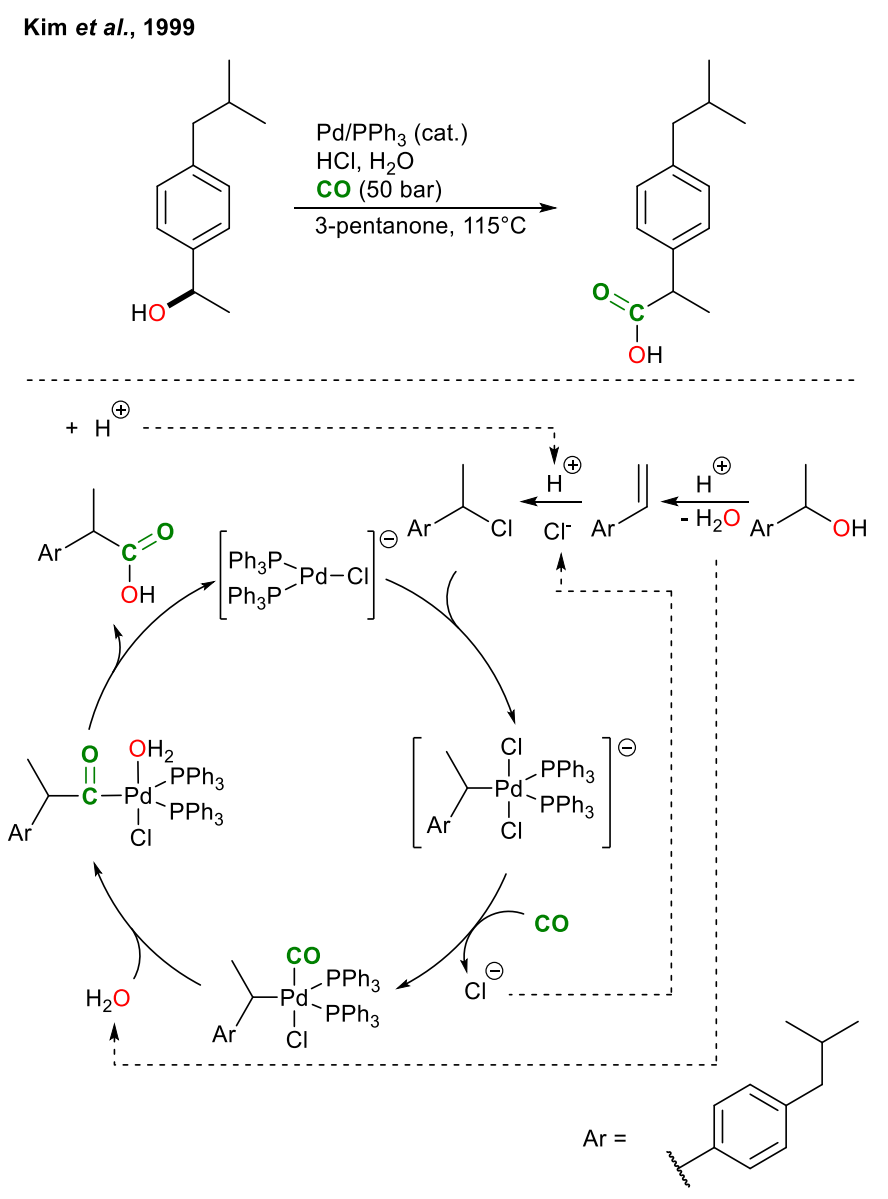

Scheme 9: Palladium catalysed carbonylation of benzylalcohols via the in situ formation of a $\mathrm{C}-\mathrm{Cl}$ bond

The carbonylation proceeds with a low valent $\mathrm{Pd}\left(\mathrm{PPh}_{3}\right)_{2} \mathrm{Cl}^{-}$ catalyst in acidic conditions, under 50 bar of $\mathrm{CO}$. The acid catalyses the dehydration of the alcohol to form an alkene that can be further converted to benzyl chloride by addition of $\mathrm{HCl}$. The $\mathrm{C}-\mathrm{OH}$ moiety is thus converted to a $\mathrm{C}-\mathrm{Cl}$ bond that will actually be carbonylated. The $\mathrm{Pd}^{0}$ active species then performs an oxidative addition on the benzyl chloride. The coordination of $\mathrm{CO}$ with concomitant abstraction of the $\mathrm{Cl}^{-}$anion followed by migratory insertion with coordination of $\mathrm{H}_{2} \mathrm{O}$ leads to the acyl intermediate. After reductive elimination and deprotonation steps, the carboxylic acid is obtained and the Brønsted acid regenerated. ${ }^{49-50}$ 
The atom efficiency of ibuprofen synthesis increased from 40 to $77 \%$ with the development of this reaction. Indeed, the process developed in 1969 (Boots Process) included 6 steps in particular including a carbene precursor that serves to introduce a single methylene group, generating stoichiometric amounts of reagents. In 1980, a new process (BHC Process, Scheme 10) with a very high atom economy was developed, including hydrogenation and carbonylation steps. Recycling the byproduct of the first step, namely acetic acid coming from an acetylation would lead to an atom efficiency of $100 \% .^{51}$

Procédé Boots/Hoechst Celanese (BHC), 1990

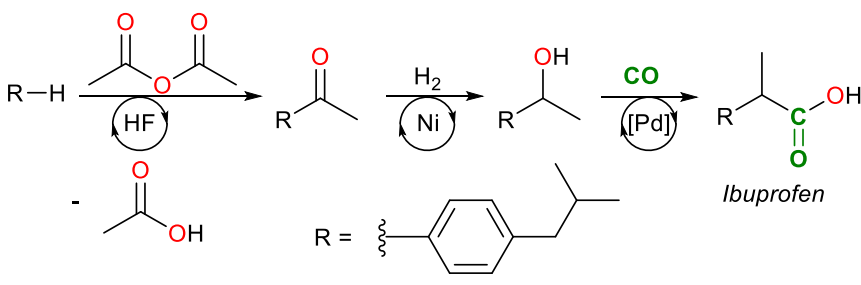

Scheme 10 : Synthesis of Ibuprofen using the highly atom-economic BHC process

An iodide-free catalyst based on $\mathrm{Rh} / \mathrm{PPh}_{3}$ has been described by Chin et al. for the carbonylation of benzyl alcohol. 52 The authors suggest that the alcohol is dehydrated, forming the benzyl ether, that is carbonylated into the corresponding ester. The latter is then hydrolysed to relase the benzyl formate and an equivalent of starting material (Scheme 11).

Chin et al., 1992

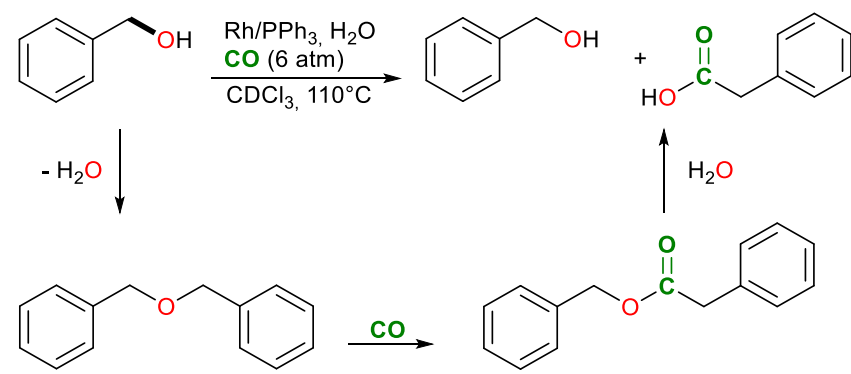

Scheme 11: An iodide-free catalytic system for the carbonylation of benzyl alcohol

In 1964, Tsuji et al. reported the carbonylation of allylic compounds, in particular allylic alcohols, esters and ethers, using Pd-based catalysts. The isomerisation of the carbonylated product demonstrated that the reaction proceeds through a $\pi$ allylpalladium intermediate that can be easily carbonylated. Nevertheless, the $\pi$-allylpalladium intermediate is then quenched by the alcohol used as solvent. ${ }^{53}$ The formal carbonylation of allylic methyl ether has later been reported at $90{ }^{\circ} \mathrm{C}$ and 80 atm of $\mathrm{CO}$ in $\mathrm{CCl}_{4}$ or toluene with [ $\left(\eta^{3}\right.$-methyl-2allyl) $\mathrm{PdCl}]_{2}$ as precursor. ${ }^{54}$ (Scheme 12 )

Tsuji et al., 1964

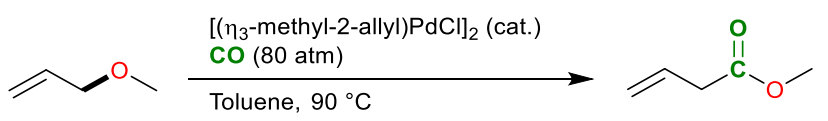

Scheme 12: Catalytic carbonylation of the $\mathrm{C}-\mathrm{O}$ bond in allylmethylether

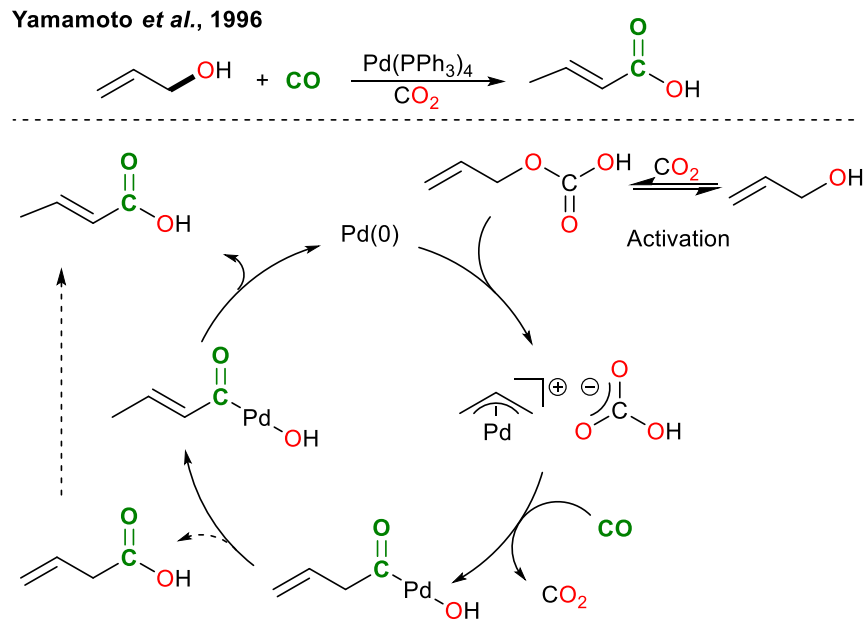

Scheme 13: Mechanism of the $\mathrm{CO}_{2}$-assisted carbonylation of allylic alcohols

In 1996, Yamamoto et al. reported the Pd-catalysed carbonylation of the $\mathrm{C}-\mathrm{O}$ bond of allylic alcohols promoted by $\mathrm{CO}_{2} .{ }^{55}$ The allylic ester is obtained in high yield and good selectivity under $50 \mathrm{~atm}$ of $\mathrm{CO}_{2}$ and $50 \mathrm{~atm}$ of $\mathrm{CO}$, at $110{ }^{\circ} \mathrm{C}$ in DMF. Interestingly, at the same temperature, only traces of the product are observed with $80 \mathrm{~atm}$ of $\mathrm{CO}$ in the absence of $\mathrm{CO}_{2} .{ }^{55}$ According to the authors, $\mathrm{CO}_{2}$ promotes the $\mathrm{C}-\mathrm{O}$ bond cleavage by formation of an intermediate carbonate species able to undergo a facile oxidative addition to $\pi$-allylpalladium bicarbonate complexes, as shown by Tsuji et al. in 1984 with the decarboxylation/carbonylation of allylic carbonates (Scheme 13). .56

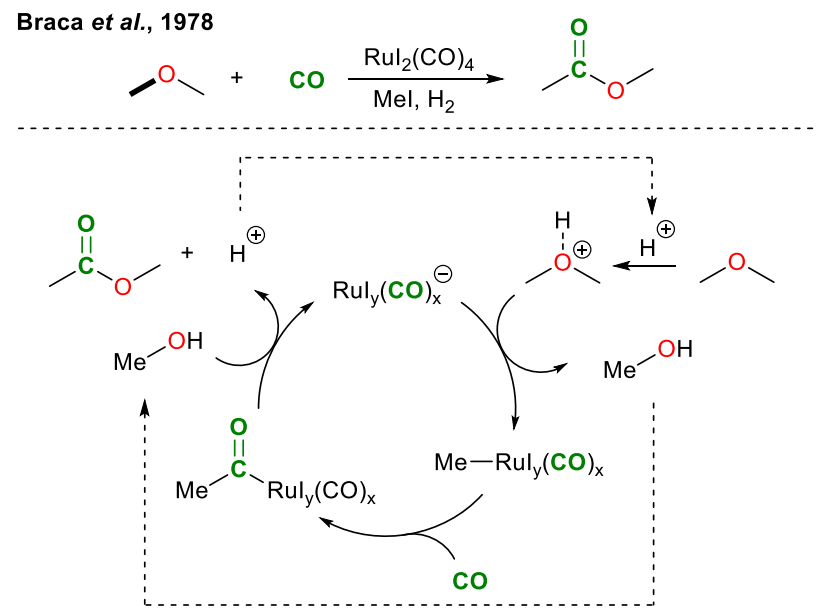

Scheme 14: Acid-assisted carbonylation of DME

\subsection{Carbonylation of unactivated $\mathrm{C}-\mathrm{O}$ bonds}

The $\mathrm{C}-\mathrm{O}$ bonds are ubiquitous in biomass and especially in the very abundant lignocellulose. ${ }^{57}$ In the perspective of fossil resources substitution, the activation of these bonds by carbonylation constitutes a challenge for the degradation of lignin and its conversion to bio-based chemicals. Moreover, the synthesis of esters from unactivated ethers through direct carbonylation could be an atom-economic way to reach these industrially relevant compounds. ${ }^{58}$ The main challenge resides 
however in the activation of the starting ethers, which feature extremely inert $\mathrm{C}-\mathrm{O}$ bonds.

\section{Carbonylation of dimethyl ether (DME)}

The carbonylation of DME to methyl acetate can be performed using similar catalytic systems as those used in the first examples for the carbonylation of the $\mathrm{C}-\mathrm{O}$ bond of methanol. Indeed, the first examples on the carbonylation of DME utilized $\mathrm{Ni}$ and $\mathrm{I}_{2}, \mathrm{Nil}_{2}$ or $\mathrm{Fel}_{2}$ at about $200{ }^{\circ} \mathrm{C}$ and $100-270$ bar $\mathrm{CO}$ to reach low yields of 10-50\%.41a, 59 In 1978, Braca et al. reported a ruthenium catalytic system with iodide and hydrogen promoters, both required for catalytic activity (Scheme 14). .0 The authors suggest an acidic activation of the ether followed by a transfer of the methyl group on the ruthenium centre, the acid being generated through hydrogenolysis of Mel. After carbonylation of the ruthenium alkyl complex, the acyl group is transferred to methanol, releasing methyl acetate and a proton. Although the mechanism proposed by the authors do not rationalize the role of iodine in the catalytic cycle, one may suggest a mechanism similar to the one described for the Monsanto and Cativa processes or the Eastman-Kodak process (see below Scheme 15). DME could react with an iodide source to form methyl iodide, which would undergo an oxidative addition on the metallic centre and is further carbonylated to generate the acyl iodide. The latter is then converted to methyl acetate through reaction with methanolate and regenerate the iodide source.
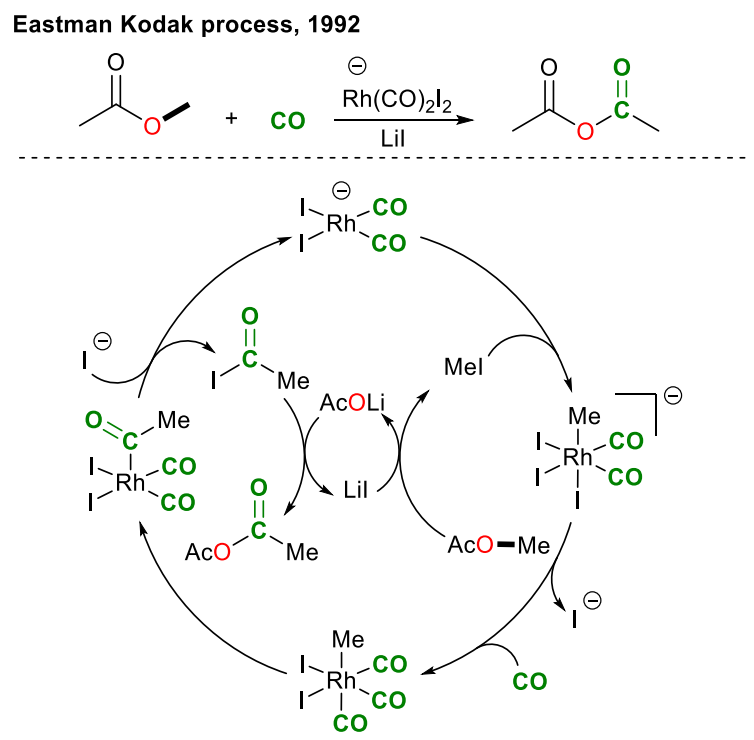

Scheme 15: Rhodium catalysed carbonylation of methyl acetate

Nevertheless, the dimethyl ether being gaseous at room temperature, heterogeneous catalysis, and gas phase reactions are preferred for the carbonylation of DME to methyl acetate. ${ }^{61}$ Methyl acetate can be carbonylated further to generate acetic anhydride, a chemical widely used in industrial chemistry for acetylation reactions or as a dehydration agent. ${ }^{62}$ This reaction is catalyzed by rhodium complexes assisted by alkyliodide promotors (Eastman Kodak Process). ${ }^{63}$ The mechanistic pathway is very the similar to the Cativa process, the only difference being that the reaction rate significantly increases upon using Lil instead of HI. ${ }^{64}$ Kinetic experiments demonstrated that the lithium cation plays a key role in the two reactions involved in the second catalytic cycle. Both the formation of methyl iodide from lithium iodide and methyl acetate, and the formation of the acetic anhydride from the acetate and the acyl iodide are highly favoured in presence of an alkali cation, and especially lithium. ${ }^{32}$

Example of carbonylation of an aryl methyl ether

Han et al., 2018

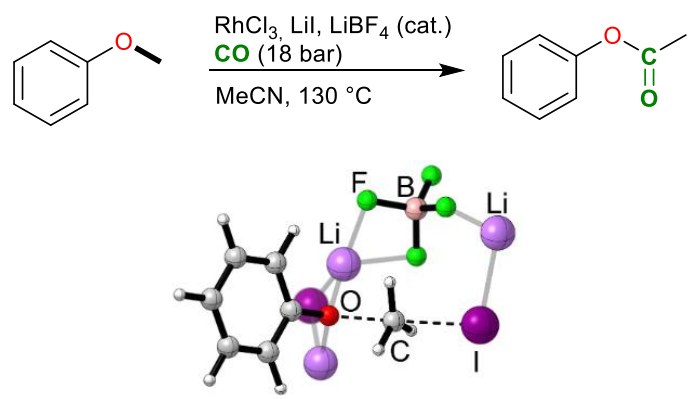

Scheme 16: C-O bond carbonylation of Phenyl methyl ester. Top: reaction conditions. Bottom: Assistance of Lil and $\mathrm{LiBF}_{4}$ in the O-Me activation.

A significant part of the $\mathrm{C}-\mathrm{O}$ bonds contained in lignin are arylalkyl-ethers and more specifically aryl-methyl-ether bonds. ${ }^{57}$ The direct carbonylation represents an appealing method for the synthesis of valuable chemicals. Very recently, the group of Han reported the carbonylation of an aromatic ether bond, using a rhodium catalyst assisted by lithium iodide and lithium tetrafluoroborate (Scheme 16, top). ${ }^{65}$ The rhodium based complexes, assisted by iodide salts, are known to be active in carbonylation reactions, as shown in the Monsanto process. Han et al. demonstrated that the joint assistance of Lil and $\mathrm{LiBF}_{4}$ allows the activation of the $\mathrm{Me}-\mathrm{O}$ bond in the aromatic ether by reducing the energy barrier for $\mathrm{C}-\mathrm{O}$ bond cleavage for producing $\mathrm{CH}_{3} \mathrm{I}$ (Scheme 16, bottom). This elegant example have previously been used for the carbonylation of methoxy groups in lignin to produce high purity acetic acid from pure $\mathrm{CO}$ or from $\mathrm{CO}_{2}$ produced in-situ by RWGS. ${ }^{66}$

To the best of our knowledge, no other example of the carbonylation of an unactivated ether has been reported so far. Conclusion on the carbonylation of $\mathrm{C}-\mathrm{O}$ bond

The carbonylation of $\mathrm{C}-\mathrm{O}$ bonds has been widely studied over the last century and is used nowadays at industrial scale. Various strategies depending on the nature of the $\sigma$ bond have been developed to face the challenge of their carbonylation. The carbonylation of $\mathrm{O}-\mathrm{Me}$ bonds is generally performed using rhodium catalysts together with an iodide source, palladiumbased catalysts are effective for the allylic and benzylic substrates, and cobalt catalysts assisted by a Lewis acid are preferred for the carbonylation of cyclic substrates. Reactions are however usually involving high pressures and temperatures, and further development is needed in order to be able to carbonylate more sensitive and polyfunctionalized substrates such as lactic acid, and to use less demanding conditions. A deep understanding of the mechanisms involved and of the 
requirements for an optimization of the catalytic systems will allow discovery of new reactivities working in mild conditions.

\subsection{Carbonylation of $\mathrm{N}-\mathrm{H}$ bonds}

Using $\mathrm{CO}$ as a formylating agent is the most efficient way to synthesize formamides from readily available primary or secondary amines. In 1966, Hirota et al. demonstrated that copper salts catalyse the carbonylation of alkylamines, under 60 bar CO at $140{ }^{\circ} \mathrm{C} .{ }^{67}$ Moreover, many others metals have shown to be efficient in this reaction, including $\mathrm{Rh},{ }^{68} \mathrm{Fe},{ }^{69} \mathrm{Ni},{ }^{70}$ $\mathrm{Zn}^{71}$ and $\mathrm{Ru} .{ }^{72}$

Wu et al., 2015

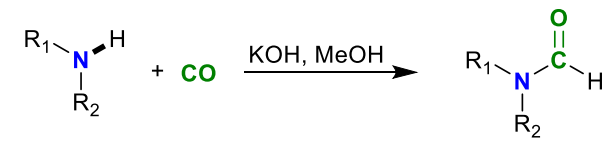

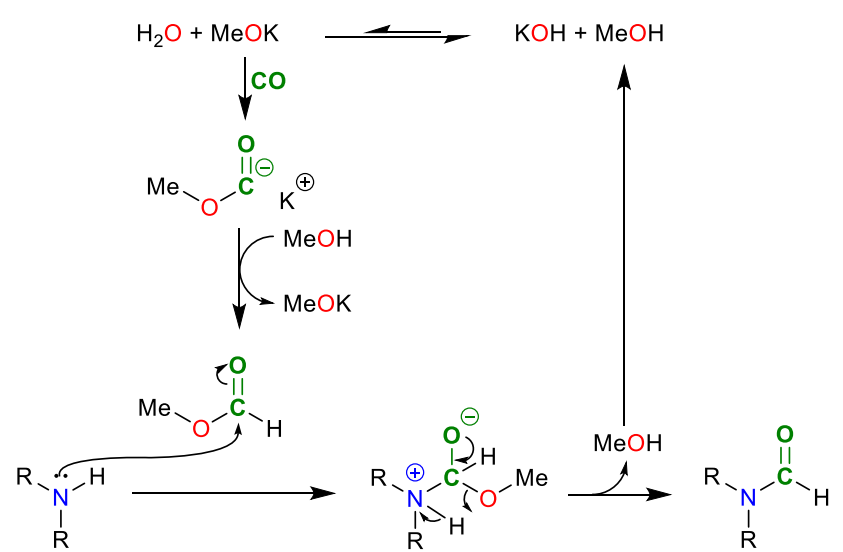

Scheme 17: Mechanism of $\mathrm{KOH} / \mathrm{MeOH}$ catalyzed carbonylation of amines.

Transition metal-free catalysts are also efficient for the carbonylation of primary and secondary amines. For example, the use of $\mathrm{NaOMe}$ has been described in several patents dealing with the carbonylation of dimethylamine to dimethylformamide (DMF). ${ }^{73}$ The use of heterocyclic carbenes and ionic liquids based on imidazolium salt has also been considered. ${ }^{74}$ In 2015, Wu et al. developed a new catalytic system using inorganic bases $\left(\mathrm{KOH}, \mathrm{NaOH}, \mathrm{Na}_{2} \mathrm{CO}_{3}, \mathrm{~K}_{2} \mathrm{CO}_{3}\right)$ as catalysts for the carbonylation of a significant number of substrates under 10 bar of $\mathrm{CO}$ at $110^{\circ} \mathrm{C} .7^{75}$ The mechanism actually involves the previously presented carbonylation of methanol to methyl formate, with the latter product undergoing an amidification reaction that liberates $\mathrm{MeOH}$ and the formamide.

\subsection{Carbonylation of activated $\mathrm{C}-\mathrm{N}$ bonds}

\section{Carbonylation of benzylic and allylic $\mathrm{C}-\mathrm{N}$ bonds}

The carbonylation reaction of acyclic amines was first developed on activated amines. Indeed, in 1984, a BASF patent described the selective carbonylation of the benzylic position of the 2-((dimethylamino)methyl)phenol to yield 2-(2hydroxyphenyl)-acetamide (Scheme 18$).{ }^{76}\left[\mathrm{Co}_{2}(\mathrm{CO})_{8}\right]$ was used as a catalyst under 220 bar of $\mathrm{CO}$ and $120^{\circ} \mathrm{C}$.

In the same way, Nishimura showed that allyl amines can be carbonylated into $\alpha, \beta$-unsaturated amides by using palladium complexes supported by phosphines under 50 bar of $\mathrm{CO}$ at $110^{\circ} \mathrm{C}^{77}$ (Scheme 18) The optimization of the reaction conditions led to the development of an efficient strategy for allyl amines carbonylation under only 10 bar of $\mathrm{CO}$ and at $120{ }^{\circ} \mathrm{C}$, using $\left[\mathrm{Pd}(\right.$ XantPhos $\left.) \mathrm{Cl}_{2}\right]$ as a catalyst. ${ }^{78} \mathrm{~A}$ mechanistic study from the group of Nishimura showed the implication of a $\pi$-allyl palladium intermediate that facilitates the $\mathrm{C}-\mathrm{N}$ bond activation. ${ }^{77 b}$ Nevertheless, only the linear product is accessible by this reaction.

BASF, 1984<smiles>CN(C)Cc1ccccc1O</smiles>

Nishimura et al., 1994

$$
\text { Dpp : 1,3-Bis(diphenylphosphino)propane }
$$

Scheme 18: Benzylic and Allylic $\mathrm{C}-\mathrm{N}$ bond carbonylation

More recently, Huang et al. developed an elegant carbonylation of benzylamines with nickel catalyst and iodine (Scheme 19). ${ }^{79}$ Although the mechanism is not fully understood, the authors proposed that iodine activates the benzylamine, through the formation of an intermediate charge-transfer complex. The electron-transfer to iodine facilitates the cleavage of the $\mathrm{C}-\mathrm{N}$ bond by the $\mathrm{Ni}$-complex forming a radical-containing complex. After migratory insertion and further reaction of the benzyl radical on the $\mathrm{Ni}$-center, a reductive elimination step delivered the amide and regenerated the $\mathrm{Ni}$-catalyst.

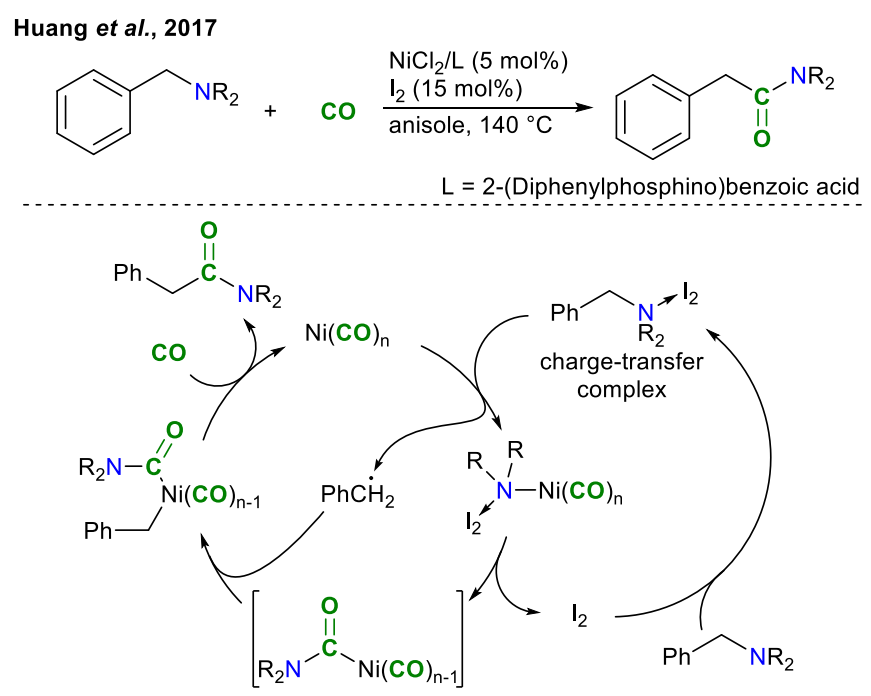

Scheme 19: Benzylamine carbonylation through formation of a charge-transfer complex

\section{Carbonylation of aziridines}

The direct formation of lactams from cyclic amines such as aziridines, azetidines, pyrrolidines and related compounds occurs with much more ease. Indeed, the direct carbonylation of such compounds has been observed under mild conditions in 
the sole presence of cobalt carbonyl or other carbonyl complexes. ${ }^{80}$ For example, the carbonylation of $\mathrm{N}$-methyl-2phenylazetidine was catalyzed by $\left[\mathrm{CO}_{2}(\mathrm{CO})_{8}\right]$ under 3.5 bar of $\mathrm{CO}$ at $90^{\circ} \mathrm{C}$, when the carbonylation of the corresponding oxetane required the joint use of of an activator (salen $\mathrm{Al}$ complex) and harsher conditions (14 bar CO). ${ }^{40}$

\subsection{Carbonylation of alkyl and aryl amines}

Although the catalytic carbonylation of several $\mathrm{C}-\mathrm{N}$ bonds are known when the amines are activated, only few methods have been described starting from tertiary non-activated amines. ${ }^{81}$ This observation can be rationalized by the fact that the carbonylation of a tertiary amine requires the breaking of a $\mathrm{C}-$ $\mathrm{N}$ bond to insert $\mathrm{CO}$. However, the $\mathrm{C}-\mathrm{N}$ bonds in allylic and benzylic molecules are more reactive than in simple alkylamines, this is explained by comparing their respective BDEs: while the BDE of the benzyl- $\mathrm{N}\left(\mathrm{CH}_{3}\right)_{2}$ linkage is about 255 kJ.mol-1, it reaches $272 \mathrm{~kJ}^{-\mathrm{mol}^{-1}}$ for $\mathrm{CH}_{3}-\mathrm{N}\left(\mathrm{CH}_{3}\right) \mathrm{Ph}$. In 1968, a Shell patent showed that $\left[\mathrm{CO}_{2}(\mathrm{CO})_{8}\right]$ can catalyse the carbonylation of trimethylamine (TMA) to DMF under harsh conditions $\left(\mathrm{T}>150^{\circ} \mathrm{C}, \mathrm{P}(\mathrm{CO})>85\right.$ bar and 1 eq of water)..$^{82}$ In 1984, Bellis optimized the previous Shell process for TMA carbonylation, by using catalytic amounts of water under harsh condition (i.e $0.5-2.0 \mathrm{~mol}$ of water per mol of $\left[\mathrm{Co}_{2}(\mathrm{CO})_{8}\right], \mathrm{T}>$ $250^{\circ} \mathrm{C}, \mathrm{P}(\mathrm{CO})>85$ bar), however at the cost of an increased reaction temperature. ${ }^{83}$ The use of water as promotor of the reaction is explained by the supposed in situ formation of $\left[\mathrm{HCo}(\mathrm{CO})_{4}\right](\mathrm{pKA}=8.3) .{ }^{84}$ This hydride cobalt carbonyl complex might indeed react as a weak acid and promote the activation of the $\mathrm{C}-\mathrm{N}$ bond by protonating the amine, to form $\left[\mathrm{Co}\left(\mathrm{CH}_{3}\right)(\mathrm{CO})_{4}\right]$ (Scheme 20).

A similar strategy has been demonstrated in 2014 for the carbonylation of amines, when Li's group developed a carbonylation process using quaternary ammonium compounds in the presence of in situ prepared nucleophilic catalysts based on $\mathrm{Pd}^{0}$ and $\mathrm{CO}^{-1} .85$ These reactions were performed under a $\mathrm{CO}$ pressure over 30 bar, for most examples, and high temperatures $\left(>190^{\circ} \mathrm{C}\right)$. Finally, the scope of the reaction remained limited to a few examples. Co and Pd catalysts have subsequently been used for the carbonylation of tertiary amines such as trimethylamine. The use of $\mathrm{PdCl}_{2}$ coordinated by 2,2'-bipyridine assisted by an ammonium iodide salt as iodide source made it possible to obtain good yields of dimethylacetamide. ${ }^{86}$ Li's group also described the catalytic carbonylation of trimethylamine with $\mathrm{Na}\left[\mathrm{Co}(\mathrm{CO})_{4}\right]$, in presence of a iodinated ammonium combined with a Lewis acid as promotor (Scheme 22), which can be extended to the carbonylation of some tertiary, aromatic and aliphatic tertiary amines. ${ }^{87}$ This synthetic route greatly improves the atomeconomy of the carbonylation reaction of tertiary amines. Very recently, our group used the dianion $\mathrm{K}_{2}\left[\mathrm{Fe}(\mathrm{CO})_{4}\right]$ to perform the carbonylation of various amines at low pressure ( 8 bar), in the presence of $\mathrm{Mel}$ as an activating agent and $\mathrm{Nd}(\mathrm{OTf})_{3}$ as a cocatalyst. ${ }^{88}$ The requirement of an iodide promotor indicates that the catalyst does not directly activates the $\mathrm{C}-\mathrm{N}$ bond, but that the latter is converted to a more reactive $\mathrm{C}-\mathrm{I}$ bond.

\section{Bellis, 1985}

Generation of the active species:

$$
\begin{aligned}
\mathrm{Co}_{2}(\mathrm{CO})_{8}+\mathrm{H}_{2} \mathrm{O}+\mathrm{CO} & \longrightarrow 2 \mathrm{HCo}(\mathrm{CO})_{4}+\mathrm{CO}_{2} \\
\mathrm{HCo}(\mathrm{CO})_{4}+\mathrm{Me}_{3} \mathrm{~N} & \longrightarrow \mathrm{Me}_{2} \mathrm{NH}+\mathrm{MeCo}(\mathrm{CO})_{4}
\end{aligned}
$$

Catalytic cycle:

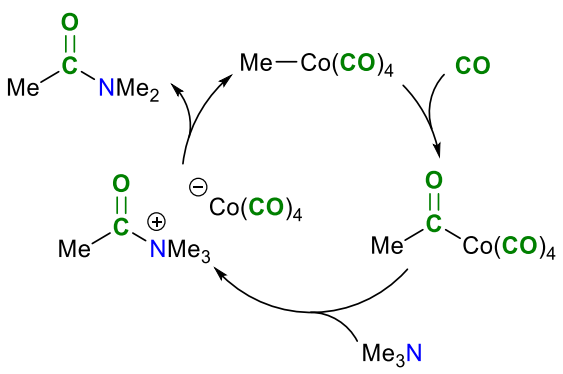

Scheme 20: Proposed mechanism for the carbonylation of amines with low valent cobalt carbonyl complexes

$$
\begin{aligned}
& \text { Li et al., } 2014
\end{aligned}
$$

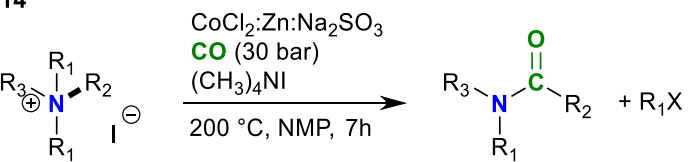

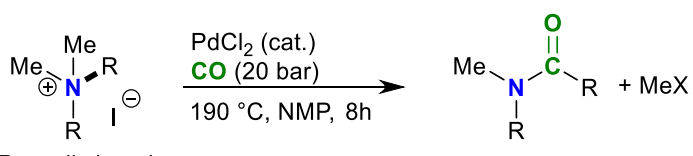

$$
\begin{aligned}
& \mathrm{R}, \mathrm{R}_{1}, \mathrm{R}_{2}, \mathrm{R}_{3}=\text { alkyl, aryl }
\end{aligned}
$$

Scheme 21: Carbonylation of alkylammonium salts as described by the group of $L$

$$
\begin{aligned}
& \text { Li et al., } 2013 \quad \mathrm{PdCl}_{2} / \text { bipy (cat.) }
\end{aligned}
$$

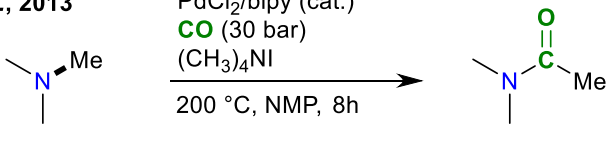

$$
\begin{aligned}
& \text { Li et al., } 2013 \quad \mathrm{Na}\left[\mathrm{Co}(\mathrm{CO})_{4}\right] \text { (cat.) }
\end{aligned}
$$

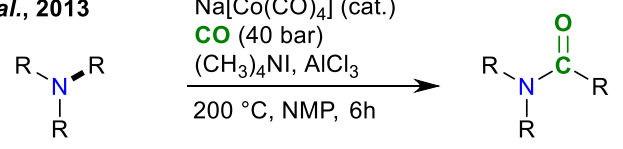

$$
\begin{aligned}
& \text { Cantat et al., } 2019 \quad \mathrm{~K}_{2}\left[\mathrm{Fe}(\mathrm{CO})_{4}\right] \text { (cat.) }
\end{aligned}
$$

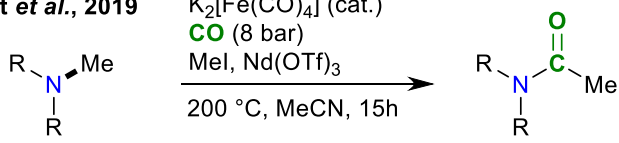

Scheme 22: lodide promoted, Pd, Co and Fe-catalyzed, carbonylation of alkylamines

\section{Conclusion on the carbonylation of $\mathrm{C}-\mathrm{N}$ bonds}

The traditional routes for the synthesis of amides generally involve chlorinating or coupling agents that are responsible of the generation of by-products and, in turn, a low atom efficiency. The direct synthesis of amides through carbonylation of the corresponding amines is atom-economic and would allow for an easy generation of amide functionalities. Activation of the $\mathrm{C}-\mathrm{N}$ bond by an external additive is often required; the main strategies reported so far implicate iodide salts promoting the formation of an ammonium intermediate that is more easily 
carbonylated. Nevertheless, the development of new activation strategies would enlarge the scope of the substrates, especially aiming at directly reacting with the $\mathrm{C}-\mathrm{N}$ bond in amines. In this perspective, one may explore bio-mimetic pathways, taking inspiration from the Wood-Ljungdahl synthesis of acetic acid, in which cobalamine promotes the carbonylation of a methylfolate intermediate by direct activation of a $\mathrm{C}-\mathrm{N}$ bond. ${ }^{89}$

2.8 Carbonylation of $\mathrm{C}-\mathrm{X}$ bonds $(\mathrm{X}=\mathrm{F}, \mathrm{Cl}, \mathrm{Br}, \mathrm{I})$

The synthesis of acyl halides is usually performed from the corresponding carboxylic acids, which are halogenated with toxic reagents such as phosgene, thionyl chloride, or phosphorus tri- or pentachloride. Their direct formation by carbonylation of the corresponding organic halide would significantly increase the atom efficiency of their synthesis. The challenge in this alternative pathway is two-fold: the catalysts used need to be able to activate $\sigma \mathrm{C}-\mathrm{X}$ bonds, but the newly formed acyl halide must not react with other species present in the reaction medium.

Carbonylation of allylic $\mathbf{C}-\mathrm{X}$ bonds

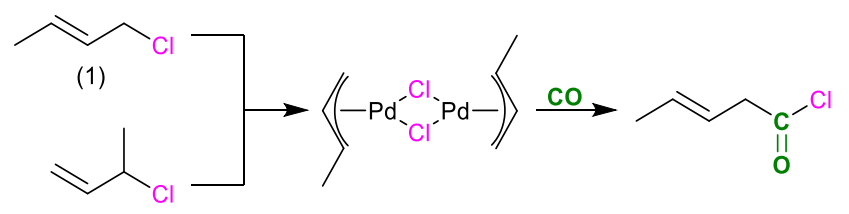

(2)

Scheme 23: Carbonylation of allyl chlorides with palladium complexes

The activation of allylic carbon-halogen bonds is made possible by the use of nucleophilic catalysts through an $\mathrm{S}_{N} 2$ mechanism or an oxidative addition. The favourable thermodynamics of the oxidative addition of the Pd catalyst leading to the formation of a stable $\pi$-allyl intermediate facilitate the $\mathrm{C}-\mathrm{Cl}$ bond cleavage (Scheme 23). This was demonstrated by Whitfield et al. who described the formation of a $\pi$-allyl intermediate upon carbonylation of the 1-chlorobut-2-ene (1) or the 3-chlorobut1-ene (2) to pent-3-enoyle, limiting the scope of this reaction..$^{90}$ Carbonylation of aliphatic $\mathbf{C}-\mathbf{X}$ bonds

First results demonstrating the feasibility of the carbonylation of alkylhalide derivatives were obtained with tert-butyl chloride. ${ }^{91}$ The synthesis of the pivaloyl halide was possible in the presence of a stoichiometric amount of a Lewis acid (i.e. $\left.\mathrm{AlCl}_{3}, \mathrm{BF}_{3}, \mathrm{FeCl}_{3}\right)$ or a $\mathrm{Br} \varnothing$ nsted acid $\left(\mathrm{RSO}_{3} \mathrm{H}\right)$ under a high $\mathrm{CO}$ pressure ( $>200$ bar). The reaction mechanism begins with the abstraction of the halogen atom via a heterolytic cleavage of the $\mathrm{C}-\mathrm{X}$ bond according to an $\mathrm{S}_{\mathrm{N}} 1$ type mechanism leading to the formation of a stabilized tertiary carbocation (Scheme 24).

$\mathrm{CO}$ then reacts with the carbocation to generate an acylium intermediate, which is trapped by the halide anion to yield the corresponding acyl halide. The $\mathrm{C}-\mathrm{X}$ activation step is reminiscent of the Koch reaction, that is used to produce carboxylic acids from alkenes and carbon monoxide at industrial scale (150000 t/year in 2003). ${ }^{92}$ This strategy has been used catalytically for the synthesis of a haloacetyl halides via the reaction between $\mathrm{CO}$ ( $900 \mathrm{bar}$ ), carbon tetrachloride and $10 \mathrm{~mol} \%$ of $\mathrm{AlCl}_{3}$ at $200{ }^{\circ} \mathrm{C} .{ }^{91}$ However, the reaction requires harsh reaction conditions and affords only low yields and a low selectivity. The carbonylation of primary and secondary alkyl halides has been described to occur in the presence of strong Lewis acids such as $\mathrm{AlCl}_{3}$, under 50 bar of $\mathrm{CO}$ at $50{ }^{\circ} \mathrm{C} .{ }^{93}$
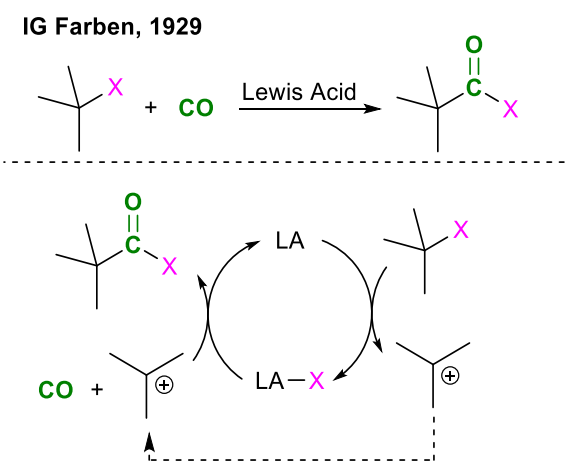

$\mathrm{X}=\mathrm{Cl}, \mathrm{Br}$

$\mathrm{LA}=\mathrm{Lewis}$ Acid $\left(\mathrm{AlCl}_{3}, \mathrm{BF}_{3}, \mathrm{FeCl}_{3}\right.$, etc. $)$

Scheme 24: Lewis Acid catalyzed carbonylation of tertiary alkyl halides

\section{Conclusion on the carbonylation of $\mathrm{C}-\mathrm{X}$ bonds}

Acyl halides are common starting materials in organic synthesis. Their production from the corresponding halide by carbonylation significantly reduces the amount of by-products generated by the use of chlorinated agent. Nevertheless, very few examples of direct carbonylation of $\mathrm{C}-\mathrm{X}$ bonds are reported in the literature, and they require both harsh conditions and stoichiometric amounts of Lewis acids. They are moreover mostly limited to tertiary alkyl halides as substrates. The carbonylation of halides in mild conditions with a catalytic system would improve the atom-economy of the synthesis of organic compounds. An interesting route would be to use the knowledge gathered in the carbonylation of $\mathrm{C}-\mathrm{O}$ and $\mathrm{C}-\mathrm{N}$ bonds that often uses $\mathrm{C}-\mathrm{I}$ as reactive intermediates, and transfer it to synthesis of acyl halides. The main challenge lies however in the intrinsic reactivity of the acyl halides, which must be controlled in order to synthesize them form such routes.

\subsection{Perspectives in the carbonylation of polar bonds}

The carbonylation of polar bonds is an active field of research, for which a number of reactions are used at industrial scale. Most catalytic strategies rely however on the use of Lewis acid co-catalysts that are required to activate the $\sigma$ bond, or iodide sources utilized to generate a more reactive intermediate. The latter strategy suffers from major drawbacks, including a low functional group tolerance, and the use of variable amounts of additives, which have to be recycled or disposed of at the end of the process. New activation pathways need to be found, to widen the scope of reactive substrates without resorting to cocatalysts. Moreover, activation of highly stable bonds such as those in ethers remain a challenge, but their carbonylation would lead to greener and atom-economic routes towards complex, high-value chemicals. 


\section{Carbonylation of non-polar substrates}

\subsection{Challenges in the activation of non-polar substrates}

The carbonylation of polar substrates through transition metal catalysis is a challenge due to selectivity issues and inherent moderate reactivity of some substrates such as amines. Still, these can be overcome using various promotors as shown above. The carbonylation of non-polar substrates is, however, a long-standing challenge. Indeed, the lack of reactivity and the ubiquity of a number of non-polar bonds in a molecule, such as $\mathrm{C}-\mathrm{H}$ or $\mathrm{C}-\mathrm{C}$ bonds, poses unsolved efficiency and selectivity issues. In addition, the stability of such inert bonds may present thermodynamic limitation, as the inherent exotherm of the carbonylation reaction can be low, and in some cases disfavoured (vide infra). High pressures or temperatures will then be required in order to shift the thermodynamics of the reaction towards a productive carbonylation.

\subsection{Dihalogens}

Table 1: Exergonicity of the carbonylation of dihalogens

\begin{tabular}{cc}
$\mathrm{X}_{2}+\mathrm{CO} \stackrel{\Delta \mathrm{G}_{298}}{\longrightarrow} \mathrm{X}^{-\mathrm{C}} \mathrm{I} \mathrm{X}$ \\
\hline Dihalogen $\mathrm{X}_{2}$ & $\Delta \mathrm{G}_{298}\left(\mathrm{~kJ}_{\mathrm{mol}} \mathrm{m}^{-1}\right)$ \\
\hline $\mathrm{F}_{2}$ & -487.3 \\
$\mathrm{Cl}_{2}$ & -68.7 \\
$\mathrm{Br}_{2}$ & +6.1 \\
$\mathrm{I}_{2}$ & +68.3
\end{tabular}

Data taken from ref 94

The carbonyl halide (i.e. $\mathrm{C}(\mathrm{O}) \mathrm{X}_{2}$ ) derivatives constitute a class of important compounds, frequently used in halogenation and acylation reactions. The change in Gibbs free energies $\left(\Delta G_{298}\right)$ associated with the carbonylation of dihalogens is however favourable for $\mathrm{F}_{2}$ and $\mathrm{Cl}_{2}$ while the reaction is endergonic for $\mathrm{Br}_{2}$ and $\mathrm{I}_{2}$ (Table 1), preventing the synthesis of $\mathrm{C}(\mathrm{O}) \mathrm{Br}_{2}$ and $\mathrm{C}(\mathrm{O}) \mathrm{I}_{2}$, the latter being known to spontaneously decarbonylate at room temperature. ${ }^{94}$ The first carbonylation of a dihalogen was reported by Davy in 1812, who described the photochemical synthesis of phosgene by exposing a mixture of $\mathrm{CO}$ and $\mathrm{Cl}_{2}$ to the sun (Scheme 25). ${ }^{95}$ The involvement of a radical mechanism was confirmed in 1965 by a trapping experiment of the radical $[\mathrm{COCl}] .{ }^{96}$

$$
\begin{aligned}
& \text { Davy, } 1812 \\
& \mathrm{Co}+\mathrm{Cl}_{2} \frac{\text { Sunlight }}{\mathrm{hv}}\left[\begin{array}{c}
\mathrm{O} \\
\mathrm{II}^{\mathrm{C}} \\
{ }_{\mathrm{Cl}}
\end{array}\right] \longrightarrow \mathrm{Cl}^{-} \stackrel{\stackrel{\mathrm{O}}{\mathrm{C}}}{{ } \mathrm{Cl}}
\end{aligned}
$$

Scheme 25: Carbonylation of $\mathrm{Cl}_{2}$ by exposition of a mixture of $\mathrm{CO}$ and $\mathrm{Cl}_{2}$ to the sun.

The carbonylation of $F_{2}$ to form carbonyl difluoride was performed using a heterogeneous copper catalyst, and is driven by the formation of strong $\mathrm{C}-\mathrm{F}$ bonds. ${ }^{97}$ The main observed impurity is $\mathrm{CF}_{4}$, obtained from the disproportionation of the product. The carbonylation of $\mathrm{Br}_{2}$ has been much less studied than its fluorinated and chlorinated counterparts because of less favourable thermodynamics. ${ }^{98}$ Nonetheless, $\mathrm{C}(\mathrm{O}) \mathrm{Br}_{2}$ is liquid at room temperature, and more easily manipulated. The first claim for its preparation was made in 1863 by Schiel, by exposing a mixture of $\mathrm{CO}$ and $\mathrm{Br}_{2}$ vapours to sunlight, similar to the previously described synthesis of phosgene. ${ }^{99}$ Vogt further improved it, demonstrating that the high-pressure reaction between $\mathrm{CO}$ and $\mathrm{Br}_{2}$ in the presence of flint glass in sealed tube at $>600{ }^{\circ} \mathrm{C}$ allows for the formation of $\mathrm{C}(\mathrm{O}) \mathrm{Br}_{2} \cdot{ }^{100}$ Finally, $\mathrm{C}(\mathrm{O}) \mathrm{I}_{2}$ has never been isolated due to its intrinsic reactivity. ${ }^{94}$ It has sometimes been proposed as a reaction intermediate, but was never directly synthesized from $\mathrm{CO}$ and $\mathrm{I}_{2} \cdot{ }^{94}$

\subsection{Carbonylation of dihydrogen}

Formaldehyde is an important molecule in the chemical industry where it is used in the manufacture of cosmetics, polymers, glues or organic synthesis. ${ }^{101}$ The current industrial synthesis of formaldehyde relies on the partial oxidation of methanol with oxygen (Formox process). The production of $\mathrm{CH}_{2} \mathrm{O}$ via this industrial process has several limitations related to the prior synthesis of methanol, the use of harsh conditions for the oxidation of methanol and a limited atom-efficiency (>50\%). ${ }^{102}$ The carbonylation of $\mathrm{H}_{2}$ would be the best and most direct pathway, and highly desirable if performed from biomass-derived syngases, because it would avoid the energy loss inherent in the Formox process, and presents an atom-efficiency of $100 \%$. It has not been considered at industrial scale because of unfavourable thermodynamics: in the gas phase, at room temperature, the exergonicity of the reaction is only $35 \mathrm{~kJ} \mathrm{~mol}^{-1}$, and increases with the temperature. Recently however, the group of Tanksale demonstrated that the use of $\mathrm{Ru}-\mathrm{Ni} / \mathrm{Al}_{2} \mathrm{O}_{3}$ in water at $80{ }^{\circ} \mathrm{C}$ under 100 bar of a $1: 1$ $\mathrm{CO} / \mathrm{H}_{2}$ mixture yielded $4.55 \mathrm{mmol} . \mathrm{L}^{-1} \cdot \mathrm{g}_{\mathrm{cat}}{ }^{-1}$ after $72 \mathrm{~h}$ at $353 \mathrm{~K}$, with $100 \%$ selectivity (Scheme 26). The equilibrium shift towards formaldehyde is due to its hydration and further conversion into methylene glycol. ${ }^{103}$

Tanksale et al., 2015

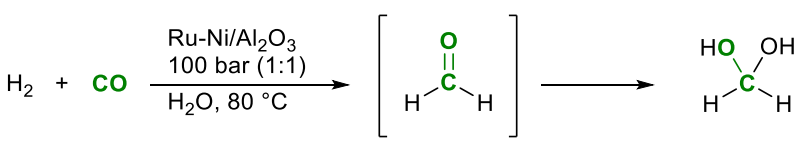

Scheme 26: Carbonylation of dihydrogen for the formation of formaldehyde.

\subsection{Carbonylation of $\mathrm{C}-\mathrm{C}$ and $\mathrm{C}-\mathrm{H}$ bonds}

The synthesis of ketones and aldehydes through the insertion of $\mathrm{CO}$ in $\mathrm{C}-\mathrm{C}$ and $\mathrm{C}-\mathrm{H}$ bonds would be of the utmost importance, as it would allow for atom economic syntheses and avoid current oxidation routes. ${ }^{104}$ It could also complement hydroformylation approaches and enable the production of benzaldehyde from benzene. However, the activation of $\mathrm{C}-\mathrm{C}$ and $\mathrm{C}-\mathrm{H}$ bonds represents a significant challenge alone, and the oxidative addition of a metallic fragment in a $\mathrm{C}-\mathrm{C}$ or a $\mathrm{C}-\mathrm{H}$ bond requires unsaturated, electron-rich complexes, for which $\mathrm{CO}$ coordination is usually favoured.

Carbonylation of strained cycles, including cyclopropanes and activated cyclobutanes

The carbonylation of strained cycloalkanes has been mostly performed in stoichiometric conditions. In 1985, the team of 
Eisch described the stoichiometric oxidative addition of a $\mathrm{Ni}^{0}$ complex into the $\mathrm{C}-\mathrm{C}$ bond of biphenylene to form the corresponding metallacycle. ${ }^{105}$ After bubbling $\mathrm{CO}$ on the cyclic intermediate, a yield of $89 \%$ of 9 -fluorenone was obtained. The reduced $\mathrm{Ni}^{0}$ complex is however trapped by $\mathrm{CO}$, preventing the closure of a catalytic cycle (Scheme 27). The same strategy has been used by other groups on cyclopropane derivatives with $\mathrm{Fe}^{106}$ and $\mathrm{Cr}^{107}$ complexes.

The first catalytic example of a $\mathrm{C}-\mathrm{C}$ bond carbonylation of cyclopropane was described in 1980 with $0.3 \mathrm{~mol} \%$ of $\left[\mathrm{Rh}(\mathrm{CO})_{2} \mathrm{Cl}\right]_{2}$ under 50 bar of $\mathrm{CO}$ and $160{ }^{\circ} \mathrm{C}$, yielding $3.6 \%$ of cyclobutanone. ${ }^{108}$ More recently, the catalytic use of $\left[\mathrm{Co}_{2}(\mathrm{CO})_{8}\right]$ has allowed via a $[3+1]$ co-cyclization of methylenecyclopropane derivatives with $\mathrm{CO}$ under milder condition ( $1 \mathrm{~atm}$ of $\left.\mathrm{CO}, 50^{\circ} \mathrm{C}\right) .{ }^{109}$ The coordination of the methylene fragment to the cobalt centre allowed for an easier activation of the endocyclic $\mathrm{C}-\mathrm{C}$ bond, leading to the formation of a cobaltocyclopropane moiety that undergoes carbonylation and further reductive elimination to release the cyclobutanone (Scheme 28).

\section{Eisch et al., 1985}

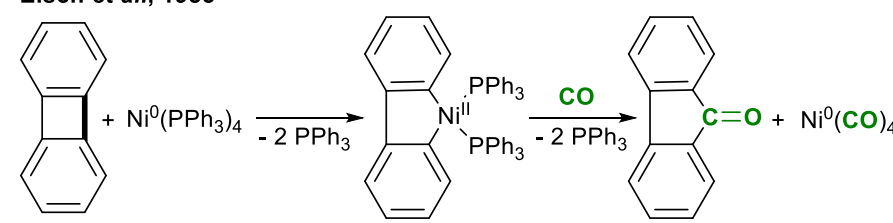

Scheme 27 : Carbonylation of the biphenylene by a nickel complex

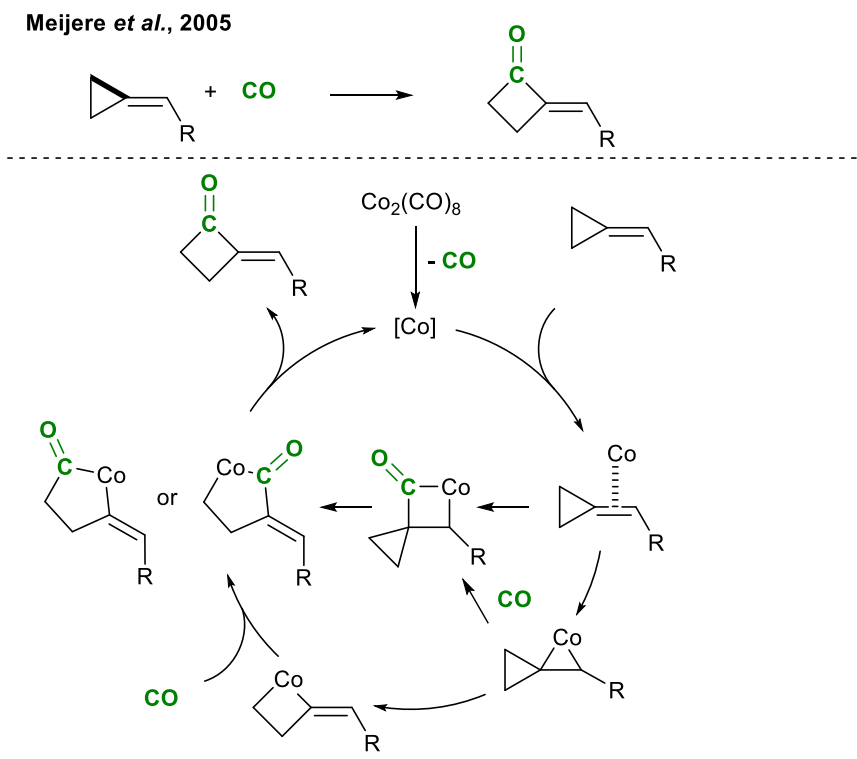

Scheme 28: Mechanism for the carbonylation of methylenecyclopropane

\section{Carbonylation of aromatic and aliphatic $\mathrm{C}-\mathrm{H}$ bonds}

In 1983, Eisenberg et al. described the use of an iridium carbonyl hydride complex, $\left[\mathrm{IrH}_{3}(\mathrm{CO})(\mathrm{dppe})\right]$, which, under light irradiation and under $1 \mathrm{~atm}$ of $\mathrm{CO}$ or syngas, converted benzene (used as a solvent) to benzaldehyde. ${ }^{110}$ (Scheme 29) The strategy was extended to other catalysts based on $\mathrm{Rh}$ and $\mathrm{Ru}$ under irradiation, leading to similar results. ${ }^{111}$ Despite a promising selectivity, yields were low. This low efficiency is linked to many factors including unfavourable thermodynamics $\left(\Delta \mathrm{G}^{\circ}=+1.7 \mathrm{kcal}^{\mathrm{mol}}{ }^{-1}\right)$, and the formation of a number of sideproducts. ${ }^{112}$

Tanaka demonstrated that a Vaska-type $\mathrm{Rh}^{\mathrm{l}}$ complex $\left[\mathrm{RhCl}(\mathrm{CO})\left(\mathrm{PMe}_{3}\right)_{2}\right]$ catalyzes the carbonylation of cyclic and linear alkanes, while having a high selectivity for terminal $\mathrm{C}-\mathrm{H}$ bonds. ${ }^{112}$ The proposed mechanism involves the formation of a 14-electron complex, $\left[\mathrm{RhCl}\left(\mathrm{PMe}_{3}\right)_{2}\right]$ formed upon photoactivation of the starting complex (Scheme 30). This unsaturated species activates the $\mathrm{C}-\mathrm{H}$ bond of benzene (or of the alkane), to form an hydrido aryl (or hydrido alkyl) complex. Under $\mathrm{CO}$, carbonylation of the $\mathrm{Rh}-\mathrm{C}$ bond can occur, and further reductive elimination leads to the corresponding aldehyde and regeneration of the active species. ${ }^{113}$ In this case, the photolysis of CO from the starting complex allows the generation of a sufficiently reactive complex that can react with $\mathrm{C}-\mathrm{H}$ bonds, closely related to species already described by Bergman or Jones. ${ }^{114}$

Eisenberg et al., 1983
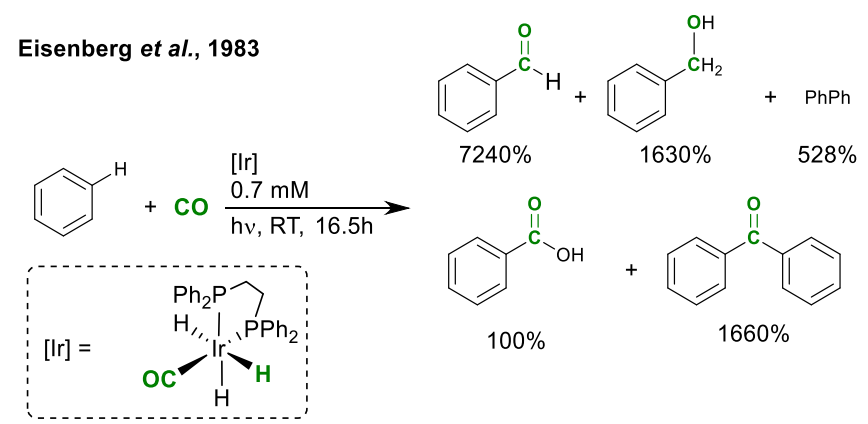

Tanaka et al., 1990
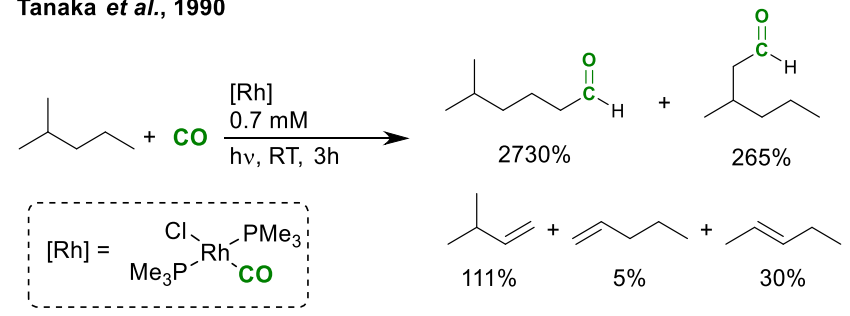

Scheme 29: Rhodium catalyzed photocarbonylation of $\mathrm{C}-\mathrm{H}$ bonds. Percentages calculated compared to the catalyst.

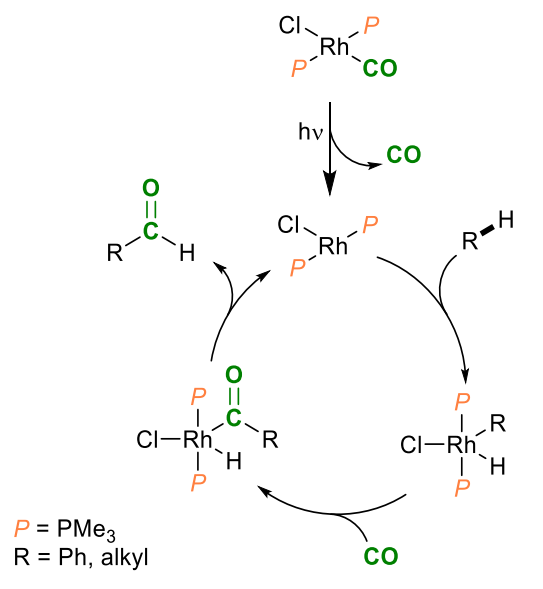

Scheme 30: Mechanism for the photocatalytic carbonylation of $\mathrm{C}-\mathrm{H}$ bonds 
A second approach developed by the group of Olah and Prakash utilizes superacids. $\mathrm{HF} \cdot \mathrm{BF}_{3}$ is indeed able to protonate $\mathrm{CO}$ and generate the linear carboxonium ion $\mathrm{HCO}^{+}$. The latter is a superelectrophilic formylating agent that can react with the $\mathrm{C}-$ $\mathrm{H}$ bond of isobutane and form pivalaldehyde. An acid-catalyzed rearrangement leads further to methyl isobutyl ketone. ${ }^{115}$ An analogous approach was used for the carbonylation of toluene to $p$-tolualdehyde in pure triflic acid by the group of White. ${ }^{116}$ Yet, extension of this strategy to more complex molecules is not trivial due to the sensitivity of functional groups towards superacids.

\section{Conclusions and perspectives}

Over the course of this perspective, we showed that the direct carbonylation of $\sigma$ bonds can be highly atom economic for the synthesis of high-value carbonyl-containing chemicals. Although a myriad of carbonylation reactions have been developed using transition metal catalysts, the carbonylation of $\sigma$ bonds remains a significant challenge due to the inert nature of $\sigma$ bonds. Successful examples of such transformations rely on either the use of Lewis acid co-catalysts or the utilization of alkyliodide promotors. These strategies allow the carbonylation of a number of simple molecules such as methanol, DME or anisoles, but more complex substrates remain a challenge. The activation and subsequent carbonylation of very inert bonds such as $\mathrm{C}-\mathrm{H}$ or $\mathrm{C}-\mathrm{C}$ bonds is poorly described so far, in part due to the inherent endergonicity of the reaction.

Further research in the field should focus on two main points. On one hand, developing additive-free and selective routes would allow the carbonylation of complex substrates, leading to an extension of the scope of such reactions. On the other hand, an effort on the carbonylation of unactivated $\sigma$ bonds will allow for the spreading of these greener routes to the formation of high-value chemicals in a simpler and more efficient way compared to the current oxidation pathways. To perform this deed, different fields of chemistry such as photochemistry, radical chemistry or electrochemistry will have to be involved, to overcome the difficulties that have been outlined in the carbonylation of $\sigma$ bonds. The main challenges will deal with the design of catalysts able to carbonylate poorly reactive $\sigma$ bonds, while leaving a number of functional groups untouched. A particular focus should be made on functional groups coming from bio-based substrates, such as aldehydes, alcohols or carboxylic acids.

These substrates can be used as useful carbon sources for the production of high-value chemicals, but the question will remain of the sourcing of $\mathrm{CO}$. In the perspective of substituting fossil resources in the chemical industry, it appears as an appealing alternative carbon source, possibly coming from $\mathrm{CO}_{2}$ (electro)reduction or biogas gasification (See Introduction for details). A challenge in bringing these reactions incorporating green $\mathrm{CO}$ in bio-based chemicals to an industrial scale will also lie in mastering the coupling of such processes, e.g. the production and utilisation of $\mathrm{CO}$, with new catalysts able to cope with the presence of contaminants in the gas stream.

\section{Conflicts of interest}

There are no conflicts to declare.

\section{Acknowledgements}

For financial support of this work, we acknowledge the CEA, CNRS, and the European Union (Carbon4PUR project, Grant agreement $n^{\circ} 768919$; ERC project ReNewHydrides, Grant agreement $\left.n^{\circ} 818260\right)$.

\section{Notes and references}

1 dena (German Energy Agency), Feedstocks for the chemical industry, 2019.

2 (a) Food and Agriculture Organization, Journal, 2019; (b) A. Bazzanella and D. Krämer, Technologies for sustainability and climate protection - chemical processes and use of $\mathrm{CO}_{2}$, DECHEMA, 2019.

3 J.-B. Peng, H.-Q. Geng and X.-F. Wu, Chem, 2019, 5, 526-552.

4 J. Hagen, Industrial catalysis: A practical approach, John Wiley \& Sons, 2015

5 Carbon monoxide, J. Bierhals, in Ullmann's encyclopedia of industrial chemistry, 2001.

6 (a) 6 - biomass gasification, Y. Neubauer, in Biomass combustion science, technology and engineering, ed. L. Rosendahl, Woodhead Publishing, 2013, pp. 106-129; (b) A. Molino, S. Chianese and D. Musmarra, J. Energy Chem., 2016, 25, 10-25.

7 (a) G. Lopez, M. Artetxe, M. Amutio, J. Alvarez, J. Bilbao and M. Olazar, Ren. Sust. Energy Rev., 2018, 82, 576-596; (b) C. Block, A. Ephraim, E. Weiss-Hortala, D. P. Minh, A. Nzihou and C. Vandecasteele, Waste and Biomass Valorization, 2019, 10, 483-509.

8 (a) G. J. S. Dawes, E. L. Scott, J. Le Nôtre, J. P. M. Sanders and J. H. Bitter, Green Chem., 2015, 17, 3231-3250; (b) X. Zhang, F. Jordan and M. Szostak, Organic Chemistry Frontiers, 2018, 5, 2515-2521; (c) A. Börner and R. Franke, Hydroformylation: Fundamentals, processes, and applications in organic synthesis, John Wiley \& Sons, 2016.

9 J. Artz, T. E. Müller, K. Thenert, J. Kleinekorte, R. Meys, A. Sternberg, A. Bardow and W. Leitner, Chem. Rev., 2018, 118, 434-504.

10 Typical contaminants in biogas include $\mathrm{H}_{2} \mathrm{~S}, \mathrm{H}_{2}$ and volatile siloxanes. (a) L. Appels, J. Lauwers, J. Degrève, L. Helsen, B. Lievens, K. Willems, J. Van Impe and R. Dewil, Ren. Sust. Energy Rev., 2011, 15, 4295-4301; (b) Global bioenergy statistics 2020, World Bioenergy Association, 2020.

11 (a) F.-Y. Gao, R.-C. Bao, M.-R. Gao and S.-H. Yu, Journal of Materials Chemistry A, 2020, 8, 15458-15478; (b) C. Costentin, M. Robert and J.-M. Savéant, Chem. Soc. Rev., 2013, 42, 2423-2436; (c) H.-R. M. Jhong, S. Ma and P. J. A. Kenis, Current Opinion in Chemical Engineering, 2013, 2, 191199.

12 (a) Phosgene, L. Cotarca, C. Lange, K. Meurer and J. Pauluhn, in Ullmann's encyclopedia of industrial chemistry, 2019, pp. 130; (b) Acetic acid, C. Le Berre, P. Serp, P. Kalck and G. P. Torrence, in Ullmann's encyclopedia of industrial chemistry, 2014, pp. 1-34; $\quad$ (c) Methanol, J. Ott, V. Gronemann, F. Pontzen, E. Fiedler, G. Grossmann, D. B. Kersebohm, G. Weiss and C. Witte, in Ullmann's encyclopedia of industrial chemistry, 2012; (d) Butanals, D. K. Raff, in Ullmann's encyclopedia of industrial chemistry, 2013.

13 R. Kungas, J. Electrochem. Soc., 2020, 167, 044508.

14 (a) C. F. J. Barnard, Organometallics, 2008, 27, 5402-5422; (b) X.-F. Wu, H. Neumann and M. Beller, Chem. Soc. Rev., 
2011, 40, 4986-5009; (c) X.-F. Wu, H. Neumann and M. Beller, ChemSusChem, 2013, 6, 229-241; $\quad$ (d) S. T. Gadge and B. M. Bhanage, RSC Advances, 2014, 4, 10367-10389;

(e) Carbonylation, M. Beller, B. A. Steinhoff, J. R. Zoeller, D. J. Cole-Hamilton, E. Drent, X.-F. Wu, H. Neumann, S. Ito and K. Nozaki, in Applied homogeneous catalysis with organometallic compounds, 2017, ch. 3, pp. 91-190; (f) J.-B. Peng, F.-P. Wu and X.-F. Wu, Chem. Rev., 2019, 119, 2090-2127; (g) Y. Li, Y. Hu and X.-F. Wu, Chem. Soc. Rev. 2018, 47, 172-194.

15 (a) N. S. Shamsul, S. K. Kamarudin, N. A. Rahman and N. T. Kofli, Ren. Sust. Energy Rev., 2014, 33, 578-588; (b) G. A. Olah, A. Goeppert and G. K. S. Prakash, Beyond oil and gas: The methanol economy, Wiley, 2018.

16 (a) J. S. Lee, J. C. Kim and Y. G. Kim, Appl. Catal., 1990, 57, 1 30; (b) Chapter 1 - catalytic methanol carbonylation, A. Haynes, in Advances in catalysis, eds. B. C. Gates and H. Knözinger, Academic Press, 2010, vol. 53, pp. 1-45.

17 (BASF AG), GB252848A, 1926.

18 S. P. Tonner, D. L. Trimm, M. S. Wainwright and N. W. Cant, J. Mol. Catal., 1983, 18, 215-222.

19 D. J. Darensbourg, R. L. Gray and C. Ovalles, J. Mol. Catal., 1987, 41, 329-347.

20 (a) Carbonylation and homologation of methanol, methyl ethers and esters in the presence of ruthenium catalysts, G. Braca, G. Sbrana, G. Valentini, G. Andrich and G. Gregorio, in Fundamental research in homogeneous catalysis, Springer, 1979, pp. 221-238; $\quad$ (b) S. J. Choi, J. S. Lee and Y. G. Kim, J. Mol. Catal., 1993, 85, L109-L116.

21 S. Jali, H. B. Friedrich and G. R. Julius, J. Mol. Catal. A: Chem., 2011, 348, 63-69.

22 It is interesting to note that the presence of water or iodide additives do not influence the yield of the reaction.

23 (a) J. Chatt and P. Chini, J. Chem. Soc. A, 1970, 1538-1542; (b) P. Chini and G. Longoni, J. Chem. Soc. A, 1970, 15421546.

24 R. A. Head and M. I. Tabb, J. Mol. Catal., 1984, 26, 149-158.

25 W. M. Haynes, Crc handbook of chemistry and physics, CRC press, 2014.

26 W. Reppe and H. Friederich, US2789137A, 1953.

27 W. Reppe, H. Friederich and W. Morsch, US2729651A, 1953.

28 F. E. Paulik and J. F. Roth, Chem. Commun. (London), 1968, 1578a-1578a.

29 D. Brodzki, B. Denise and G. Pannetier, J. Mol. Catal., 1977, 2, 149-161.

30 G. J. Sunley and D. J. Watson, Catal. Today, 2000, 58, 293-307.

31 Mechanistic pathways in the catalytic carbonylation of methanol by rhodium and iridium complexes, D. Forster, in Adv. Organomet. Chem., eds. F. G. A. Stone and R. West, Academic Press, 1979, vol. 17, pp. 255-267.

32 P. W. Van Leeuwen, Homogeneous catalysis: Understanding the art, Springer Science \& Business Media, 2006.

33 (a) H. Zabed, J. N. Sahu, A. Suely, A. N. Boyce and G. Faruq, Ren. Sust. Energy Rev., 2017, 71, 475-501; (b) Y.-S. Jang, B. Kim, J. H. Shin, Y. J. Choi, S. Choi, C. W. Song, J. Lee, H. G. Park and S. Y. Lee, Biotechnol. Bioeng., 2012, 109, 2437-2459.

34 T. W. Dekleva and D. Forster, J. Am. Chem. Soc., 1985, 107, 3565-3567.

35 (a) Biodegradable polyesters, C. Sasikala and C. V. Ramana, in Adv. Appl. Microbiol., eds. S. L. Neidleman and A. I. Laskin, Academic Press, 1996, vol. 42, pp. 97-218; (b) 5.15 biodegradable polyesters, S. Agarwal, in Polymer science: $A$ comprehensive reference, eds. K. Matyjaszewski and $\mathrm{M}$. Möller, Elsevier, Amsterdam, 2012, pp. 333-361.

36 (a) E. W. Dunn, J. R. Lamb, A. M. LaPointe and G. W. Coates, ACS Catal., 2016, 6, 8219-8223; (b) R. Zhu, J.-L. Jiang, X.-L. $\mathrm{Li}$, J. Deng and Y. Fu, ACS Catal., 2017, 7, 7520-7528; $\quad$ (c) S. Sookraj, WO2019006366A1, 2017.
37 J. T. Lee, P. J. Thomas and H. Alper, J. Org. Chem., 2001, 66 , 5424-5426.

38 J. W. Kramer, E. B. Lobkovsky and G. W. Coates, Org. Lett., 2006, 8, 3709-3712.

39 M. D. Wang, S. Calet and H. Alper, J. Org. Chem., 1989, 54, 2021.

40 Y. D. Getzler, V. Kundnani, E. B. Lobkovsky and G. W. Coates, J. Am. Chem. Soc., 2004, 126, 6842-6843.

41 (a) I. Wender and P. Pino, Organic syntheses via metal carbonyls, Interscience Publishers, 1977; $\quad$ (b) G. Jenner, H. Kheradmand and A. Kiennemann, J. Organomet. Chem., 1984, 277, 427-435

42 (a) S. Paul, Y. Zhu, C. Romain, R. Brooks, P. K. Saini and C. K. Williams, Chem. Commun., 2015, 51,6459-6479; $\quad$ (b) J. M. Longo, M. J. Sanford and G. W. Coates, Chem. Rev., 2016, 116, 15167-15197.

43 J. M. Rowley, E. B. Lobkovsky and G. W. Coates, J. Am. Chem. Soc., 2007, 129, 4948-4960.

44 J. Jiang, S. Rajendiran and S. Yoon, Asian Journal of Organic Chemistry, 2019, 8, 151-154.

45 A. Hofman, S. Słomkowski and S. Penczek, Makromol. Chem., 1984, 185, 91-101.

46 Y.-S. Lin and A. Yamamoto, Tetrahedron Lett., 1997, 38, $3747-$ 3750.

47 Y.-S. Lin and A. Yamamoto, Bull. Chem. Soc. Jpn., 1998, 71, 723-734

48 G. Papadogianakis, L. Maat and R. A. Sheldon, J. Chem. Soc., Chem. Commun., 1994, 2659-2660.

49 E. J. Jang, K. H. Lee, J. S. Lee and Y. G. Kim, J. Mol. Catal. A: Chem., 1999, 138, 25-36.

50 A. Seayad, S. Jayasree and R. V. Chaudhari, J. Mol. Catal. A: Chem., 2001, 172, 151-164.

51 (a) K. D. Rainsford, Ibuprofen: Discovery, development and therapeutics, John Wiley \& Sons, 2015; (b) M. Poliakoff and P. Licence, Nature, 2007, 450, 810-812.

52 C. S. Chin, H. J. Jung and S.-g. Hong, Bull. Korean Chem. Soc., 1992, 13, 391-395.

53 J. Tsuji, J. Kiji, S. Imamura and M. Morikawa, J. Am. Chem. Soc. 1964, 86, 4350-4353.

54 D. Medema, R. van Helden and C. F. Kohll, Inorg. Chim. Acta, 1969, 3, 255-265.

55 M. Sakamoto, I. Shimizu and A. Yamamoto, Bull. Chem. Soc Jpn., 1996, 69, 1065-1078.

56 J. Tsuji, K. Sato and H. Okumoto, J. Org. Chem., 1984, 49, 13411344.

57 J. Zakzeski, P. C. A. Bruijnincx, A. L. Jongerius and B. M Weckhuysen, Chem. Rev., 2010, 110, 3552-3599.

58 Esters, organic, W. Riemenschneider and H. M. Bolt, in Ullmann's encyclopedia of industrial chemistry, 2005.

59 N. Lassauque, PhD Thesis, Université de Toulouse, 2006.

60 (a) G. Braca, G. Sbrana, G. Valentini, G. Andrich and G. Gregorio, J. Am. Chem. Soc., 1978, 100, 6238-6240; (b) G. Braca, L. Paladini, G. Sbrana, G. Valentini, G. Andrich and G. Gregorio, Ind. Eng. Chem. Prod. Res. Dev., 1981, 20, 115-122.

61 E. Zhan, Z. Xiong and W. Shen, J. Energy Chem., 2019, 36, 5163.

62 Acetic anhydride and mixed fatty acid anhydrides, H. Held, A. Rengstl and D. Mayer, in Ullmann's encyclopedia of industrial chemistry, 2000.

63 (a) N. Rizkalla, DE2610036, 1976; $\quad$ (b) J. R. Zoeller, V. H. Agreda, S. L. Cook, N. L. Lafferty, S. W. Polichnowski and D. M. Pond, Catal. Today, 1992, 13, 73-91.

64 (a) T. H. Larkins, S. W. Polichnowski, G. C. Tustin and D. A. Young, US4374070A, 1980; (b) S. W. Polichnowski, J. Chem Educ., 1986, 63, 206

65 Q. Mei, Y. Yang, H. Liu, S. Li, H. Liu and B. Han, Science Advances, 2018, 4, eaaq0266. 
66 (a) Q. Mei, H. Liu, X. Shen, Q. Meng, H. Liu, J. Xiang and B. Han, Angew. Chem. Int. Ed., 2017, 56, 14868-14872; (b) X. Shen, Q. Meng, M. Dong, J. Xiang, S. Li, H. Liu and B. Han, ChemSusChem, 2019, 12, 5149-5156.

67 T. Saegusa, S. Kobayashi, K. Hirota and Y. Ito, Tetrahedron Lett., 1966, 7, 6125-6129.

68 D. Durand and C. Lassau, Tetrahedron Lett., 1969, 2329-\&.

69 B. D. Dombek and R. J. Angelici, J. Catal., 1977, 48, 433-435.

70 W. E. Martin and M. F. Farona, J. Organomet. Chem., 1981, 206, 393-397.

71 Y. Yoshida, S. Asano and S. Inoue, Chem. Lett., 1984, 10731076.

72 (a) Y. Tsuji, T. Ohsumi, T. Kondo and Y. Watanabe, J. Organomet. Chem., 1986, 309, 333-344; (b) G. Sussfink, M. Langenbahn and T. Jenke, J. Organomet. Chem., 1989, 368, 103-109.

73 J. Ramioulle and W. Couteau, GB1568833, 1976.

74 X. Li, K. Liu, X. Xu, L. Ma, H. Wang, D. Jiang, Q. Zhang and C. Lu, Chem. Commun., 2011, 47, 7860-7862.

75 W. Li and X.-F. Wu, Chem. Eur. J., 2015, 21, 14943-14948.

76 F. Merger, R. Kummer and H.-M. Hutmacher, EP0153476, 1984.

77 (a) S. I. Murahashi, Y. Imada and K. Nishimura, J. Chem. Soc., Chem. Commun., 1988, 1578-1579; (b) S. I. Murahashi, Y. Imada and K. Nishimura, Tetrahedron, 1994, 50, 453-464.

$78 \mathrm{H}$. Yu, G. Y. Zhang, Z. J. Liu and H. M. Huang, Rsc Advances, 2014, 4, 64235-64237.

79 H. Yu, B. Gao, B. Hu and H. Huang, Org. Lett., 2017, 19, 35203523.

80 (a) M. D. Wang, PhD Thesis, University of Ottawa (Canada), 1993; (b) Octacarbonyldicobalt, in Encyclopedia of reagents for organic synthesis, 2014, pp. 1-26; $\quad$ (c) N. Piens and M. D'Hooghe, Eur. J. Org. Chem., 2017, 2017, 5943-5960.

81 Z. Yin, J.-X. Xu and X.-F. Wu, ACS Catal., 2020, 10, 6510-6531.

82 K. Nozaki, US3412151A, 1966.

83 H. E. Bellis, CA1304408C, 1985.

84 E. J. Moore, J. M. Sullivan and J. R. Norton, J. Am. Chem. Soc., 1986, 108, 2257-2263.

85 (a) Y. Lei, R. Zhang, L. Wu, Q. Wu, H. Mei and G. Li, Appl. Organomet. Chem., 2014, 28, 310-314; (b) Y. Lei, R. Zhang, Q. Wu, H. Mei, B. Xiao and G. Li, J. Mol. Catal. A: Chem., 2014, 381, 120-125.

86 H. Mei, W. Han, J. Hu, S. Xiao, Y. Lei, R. Zhang, W. Mo and G. Li, Appl. Organomet. Chem., 2013, 27, 177-183.

87 (a) Y. Lei, R. Zhang and G. Li, International Journal of Chemical, Environmental and Biological Sciences 2013, 1, 762764; (b) Y. Z. Lei, R. Zhang, W. J. Han, H. Mei, Y. L. Gu, B. Xiao and G. X. Li, Catal. Commun., 2013, 38, 45-49.

88 T. Nasr Allah, S. Savourey, J.-C. Berthet, E. Nicolas and T. Cantat, Angew. Chem. Int. Ed., 2019, 58, 10884-10887.

89 S. W. Ragsdale and E. Pierce, Biochimica et Biophysica Acta (BBA) - Proteins and Proteomics, 2008, 1784, 1873-1898.

90 W. T. Dent, G. H. Whitfield and R. Long, J. Chem. Soc., 1964, $1588-\&$

91 E. Monflier, PhD Thesis, Université de Lille, 1992.

92 Syntheses involving carbon monoxide, in Industrial organic chemistry, 2003, pp. 127-144.

93 (a) H. Hopff and M. Dunkel, US1891930A, 1929; $\quad$ (b) (IG Farbenindustrie AG), FR671241A, 1929.

94 Carbonyl diiodide, in Topics in inorganic and general chemistry, eds. T. A. Ryan, C. Ryan, E. A. Seddon and K. R. Seddon, Pergamon, 1996, vol. 24, pp. 679-683.

95 J. Davy and H. Davy, Philos. Trans. R Soc. London, 1812, 102, 144-151.

96 Synthesis and formation of phosgene, in Topics in inorganic and general chemistry, eds. T. A. Ryan, C. Ryan, E. A. Seddon and K. R. Seddon, Pergamon, 1996, vol. 24, pp. 223-266.
97 Carbonyl difluoride, in Topics in inorganic and general chemistry, eds. T. A. Ryan, C. Ryan, E. A. Seddon and K. R. Seddon, Pergamon, 1996, vol. 24, pp. 545-664.

98 Carbonyl dibromide, in Topics in inorganic and general chemistry, eds. T. A. Ryan, C. Ryan, E. A. Seddon and K. R. Seddon, Pergamon, 1996, vol. 24, pp. 665-677.

99 J. Schiel, Liebig's Annal. Chem. Pharm., Suppl., 1863, 2, 311.

100 H. Vogt and L. Riesel, Z. Chem., 1989, 29, 342-343.

101 Formaldehyde, A. W. Franz, H. Kronemayer, D. Pfeiffer, R. D. Pilz, G. Reuss, W. Disteldorf, A. O. Gamer and A. Hilt, in Ullmann's encyclopedia of industrial chemistry, 2016, pp. 134.

102 L. E. Heim, H. Konnerth and M. H. G. Prechtl, Green Chem., 2017, 19, 2347-2355.

103 (a) A. M. Bahmanpour, A. Hoadley and A. Tanksale, Green Chem., 2015, 17, 3500-3507; (b) A. M. Bahmanpour, A. Hoadley, S. H. Mushrif and A. Tanksale, Acs Sustainable Chemistry \& Engineering, 2016, 4, 3970-3977.

104 Ketones, H. Siegel and M. Eggersdorfer, in Ullmann's encyclopedia of industrial chemistry, 2000.

105 J. J. Eisch, A. M. Piotrowski, K. I. Han, C. Kruger and Y. H. Tsay, Organometallics, 1985, 4, 224-231.

106 R. Yamaguchi, S. Tokita, Y. Takeda and M. Kawanisi, J. Chem. Soc., Chem. Commun., 1985, 1285-1286.

107 (a) P. Muller, G. Bernardinelli and Y. Jacquier, Helv. Chim. Acta, 1988, 71, 1328-1330; (b) P. Muller, G. Bernardinelli, Y. Jacquier and A. Ricca, Helv. Chim. Acta, 1989, 72, 16181626.

108 M. Hidai, M. Orisaku and Y. Uchida, Chem. Lett., 1980, 753-754

109 T. Kurahashi and A. de Meijere, Angew. Chem. Int. Ed. Engl., 2005, 44, 7881-7884.

110 B. J. Fisher and R. Eisenberg, Organometallics, 1983, 2, 764-767.

111 (a) A. J. Kunin and R. Eisenberg, Organometallics, 1988, 7, 2124-2129; (b) E. M. Gordon and R. Eisenberg, J. Mol. Catal., 1988, 45, 57-71.

112 T. Sakakura, T. Sodeyama, K. Sasaki, K. Wada and M. Tanaka, J. Am. Chem. Soc., 1990, 112, 7221-7229.

113 C. T. Spillett and P. C. Ford, J. Am. Chem. Soc., 1989, 111 1932-1933.

114 (a) J. M. Buchanan, J. M. Stryker and R. G. Bergman, J. Am. Chem. Soc., 1986, 108, 1537-1550; (b) W. D. Jones and F. J. Feher, J. Am. Chem. Soc., 1982, 104, 4240-4242.

115 G. A. Olah, G. K. S. Prakash, T. Mathew and E. R. Marinez, Angew. Chem. Int. Ed., 2000, 39, 2547-2548.

116 D. S. Sood, S. C. Sherman, A. V. Iretskii, J. C. Kenvin, D. A. Schiraldi and M. G. White, J. Catal., 2001, 199, 149-153.

\begin{tabular}{|l|l|}
\hline Picture & Biography \\
\hline Tawfiq Nasr Allah received his \\
MSc in chemistry from the \\
Paris Descartes university in \\
2015. He joined the group of \\
Thibault Cantat for his PhD, \\
where he focused on the \\
development of catalysts and \\
processes for the creation of \\
C-Cand $\mathrm{C}-\mathrm{N}$ bond through the \\
utilization of $\mathrm{CO}$ and $\mathrm{CO}_{2}$ as a \\
carbon source.
\end{tabular}




Louise Ponsard graduated
from the chemical engineer
school Chimie ParisTech in
2017 She then joined the
team of Thibault Cantat for a
PhD, focusing on the
development of novel
catalytic systems for the
carbonylation of strained
cyclic C-O bonds using
gaseous carbon monoxide
within the Carbon4PUR
project. (www.carbon4pur.eu)

